\title{
La Estructura Oropéndola en la Acrópolis de Copán
}

Ricardo Agurcia Fasquelle, Juan Carlos Pérez Calderón

\section{Resumen}

La estructura Oropéndola se ubica al interior de la Estructura 10L-16, en el centro de la Acrópolis de Copán. La construcción del edificio está fechada para mediados del Clásico Temprano; un poco más tardía que Rosalila, sugiriéndose una fecha entre el 550 y 600 d.C.Oropéndola tiene la característica de ser el primero de los edificios en Copán en cambiar el estilo de decoración del estuco modelado al mosaico en piedra, que en los siglos venideros se convirtió en el sello distintivo de Copán como uno de los centros urbanos mejor decorados y artísticos del Mundo Maya. Tanto su iconografía como su ubicación en la antigua Acrópolis muestran una clara relación del edificio con el inframundo. La imagen que prevalece es la del jaguar, animal que se asocia en el arte maya con el sol nocturno, la noche, las tinieblas, y el ámbito acuático del inframundo. Las imágenes no sólo son formas artísticas, sino que representan todo un sistema de creencias de lo que se considera fuerte, valiente y poderoso, tanto en el mundo real (el gobernante y sus guerreros) como en el supernatural. Tanto Rosalilia como Oropéndola, están marcados como montañas sagradas, witz, y tienen una multitud de otros elementos iconográficos de cosmología maya, muchos relacionados con la veneración de los antepasados y el poder de los reyes.

Palabras Clave: Copán, iconografía, inframundo, veneración de antepasados, poder real.

\section{Abstract}

The structure known as Oropéndola is located at the interior of Structure 10L-16, at the center of the Acropolis of Copan. The construction of this building is dated to the mid Early Classic; a little later than Rosalila, suggesting a date between 550 and 600 a.C. Oropéndola is characterized for being the first building in which we observed a change from modelled stucco to stone mosaics, which in following centuries became Copan's distinctive hallmark as one of the finest decorated and 
artistic urban centers of the Maya World. Both its iconography as its location in the ancient Acropolis shows a clear relation between the building and the underworld. The prevalent image is that of the jaguar, animal associated in maya art with the nocturnal sun, the night, shadows, and the aquatic realm of the underworld. The images are more than artistic forms; they also represent a whole belief system consisting of what is considered strong, brave and powerful in the real world (the ruler and his warriors) as well as in the supernatural world. Both Rosalila and Oropéndola are marked as sacred mountains, witz, and have a multitude of other iconographic elements of maya cosmology, a great deal of them related to ancestor worship and the power of kings.

Keywords: Copan, iconography, underworld, ancestor worship, royal power.

Ricardo Agurcia Fasquelle (raf@asociacioncopan.org), Juan Carlos Pérez Calderón, Asociación Copán. 


\section{INTRODUCCIÓN}

Copán (ver figura 1), declarada Patrimonio de la Humanidad desde 1980 por la UNESCO, fue inscrita bajo los criterios de ser un ejemplo sobresaliente de un conjunto arquitectónico y tecnológico, o de paisaje, que ilustra una etapa significativa en la historia humana (criterio iv), así como por estar asociado directamente con acontecimientos o tradiciones vivas, ideas, o con creencias, con trabajos artísticos y literarios de destacada significación universal (criterio vi).

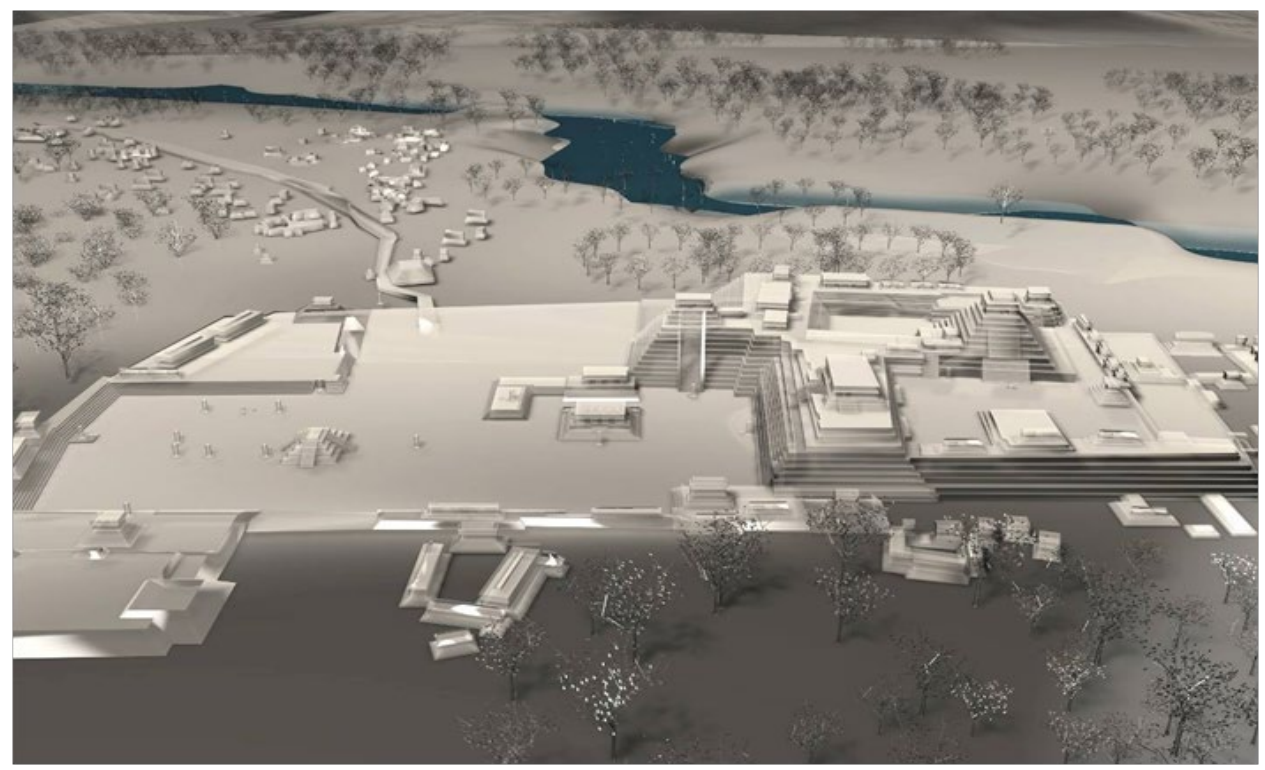

Figura 1. El Grupo Principal de Copán. (llustración: C. Gastélum).

Esos criterios trascienden hasta nuestros tiempos; Copán tiene una conexión estrecha e íntima con el Pueblo de Copán Ruinas, donde gracias a una serie de iniciativas de largo plazo, se ha generado bienestar y mejoramiento de la calidad de vida de sus pobladores. Además ha diversificado las oportunidades de desarrollo para los ciudadanos de gran parte de la región centroamericana.

En lo que concierne al Patrimonio Cultural, Copán es un referente para el mundo en materia de catalogación, registro, investigación y conservación de dicho patrimonio y tras más de 100 años de investigaciones en el sitio principal y sus áreas de influencia, esta ciudad no deja de sorprendernos. Ya sea investigando los cientos de miles de artefactos que se han recuperado a lo largo de los años o en las investigaciones arqueológicas de campo que se han y siguen llevando a cabo, esta 
antiquísima ciudad Maya del occidente de Honduras nos sigue proporcionando información y datos valiosos que, al igual que China, Egipto, el Valle del Indo y Mesopotamia, brindaron al mundo un conjunto de costumbres, saberes, y artes que nos dejaron sendas huellas del progreso material, social, cultural y político propio de las sociedades más avanzadas en la historia de la humanidad.

Copán también se ha destacado por integrar en sus investigaciones arqueológicas modernas, numerosas ciencias y técnicas de otras ramas del conocimiento. Esto ha sido particularmente cierto en la incorporación de los estudios de su magnífico arte escultórico en la interpretación arqueológica. La iconografía de sus impresionantes monumentos monolíticos tallados en piedra y las ricamente ataviadas edificaciones narra importantes detalles de las historias del poder de los gobernantes así como del sistema ideológico que los amarraba a una visión del mundo y del universo en el que ellos eran los principales actores. Las grandiosas construcciones y su arte eran el asidero del poder ideológico y político de los reyes de Copán (Miller 1986, Schele y Miller 1986, B. Fash 1992, Fash y Agurcia 1996, W. Fash 2001, Taube 2004a y 2004b).

En esta misma venia, las investigaciones arqueológicas realizadas en torno a la estructura Oropéndola, siguen hilando esta historia por medio de hallazgos que nos permiten conocer datos relevantes no sólo para la historia de esta ciudad, sino para todo el área Maya y Mesoamericana.

\section{OROPÉNDOLA}

\section{INVESTIGACIONES}

La estructura Oropéndola se ubica al interior de la Estructura 10L-16 (figura 2), al centro de la Acrópolis de Copán (figura 3). El edificio fue excavado en cuatro etapas bajo la dirección de Ricardo Agurcia F. con la asistencia de Jorge Ramos, Juan Carlos Pérez y Molly Fierer-Donaldson. La primera entre 1992 y 1996 (PAAC-PRIEM), la segunda entre 1998-2002 (PETT-16), la tercera en 2007-2008 (PDRVC) y la cuarta entre 2008-2009 (Proyecto Oropéndola). Las investigaciones se realizaron a través de túneles arqueológicos y mantuvieron una íntima vinculación con los trabajos de conservación del sitio (Agurcia Fasquelle 1997, 1998, 2004, Agurcia F. \& Fash 1991, Agurcia F. \& Pérez 2008, Agurcia, Stone \& Ramos 1996, Agurcia-Fasquelle, Sheets \& Taube 2016, Pérez Calderón 2002, 2004). 


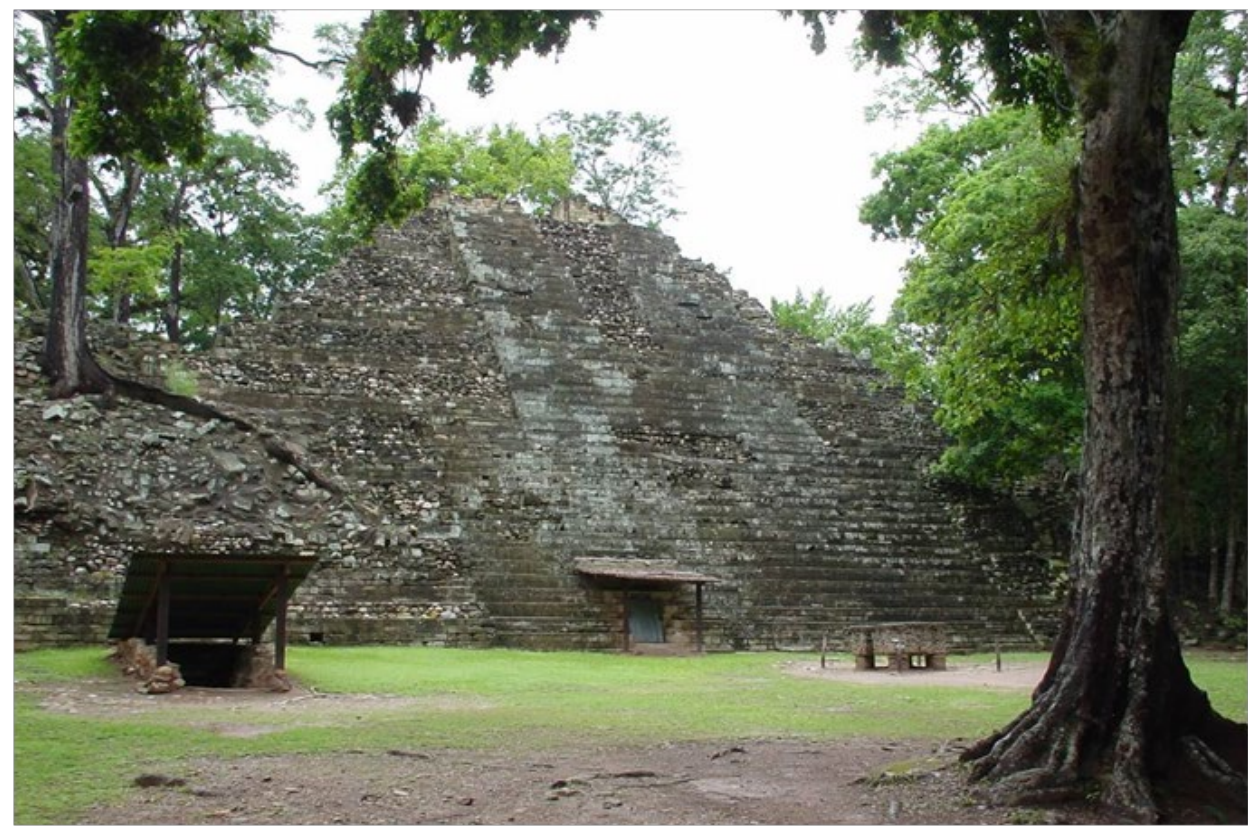

Figura 2. La Estructura 10L-16. (Foto: Ricardo Agurcia).

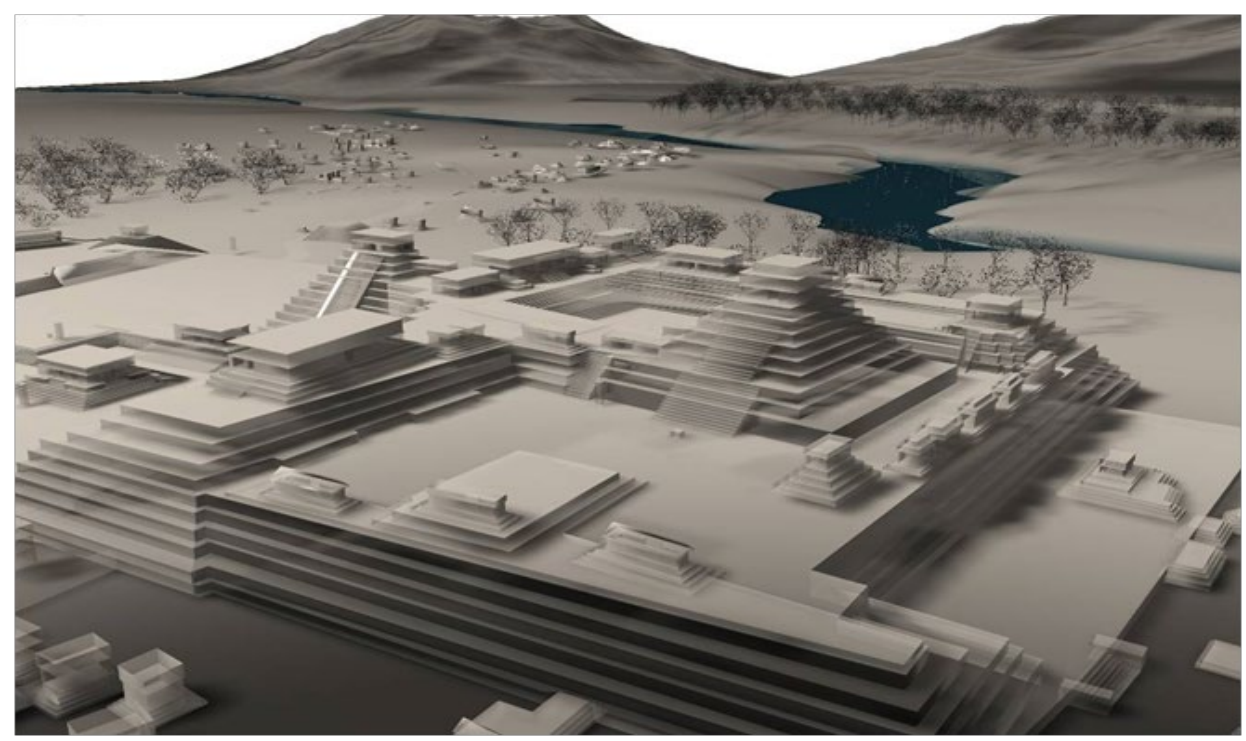

Figura 3. La Acrópolis de Copán. (Ilustración: C. Gastélum). 
Los trabajos en Oropéndola dilataron mucho debido a que los rellenos en sus alrededores (con los cuales fue sepultada por los antiguos Mayas) eran muy inestables y requerían de un enorme trabajo de consolidación para poder avanzar. Los túneles excavados en sus cercanías entre 1992 y 1996 se limitaron a definir algunas de sus dimensiones principales. En épocas recientes se acentuaron, en algunos de los túneles, nuevos problemas de estabilidad generados por diversos tipos de rellenos, invasión de raíces de árboles, filtraciones de agua, e intrusiones de animales como ratones, murciélagos, y serpientes, los cuales fueron atendidos en las últimas temporadas de trabajo. Durante el trabajo de conservación, también se obtuvo una mayor cantidad de información sobre el edificio y su historia.

Los trabajos de investigación en el Templo 16 han determinado que Oropéndola descansaba en la parte superior de una gran plataforma elevada llamada Masisoll cuya superficie tenía aproximadamente 2,750 m2 (55X50m), siendo esta la cumbre de la Acrópolis del sexto siglo en Copán (figura 4). En la parte superior había un pequeño patio rectangular de apenas $150 \mathrm{~m} 2$ (25X6 m) que era delimitado en su costado oeste por la Estructura Rosalila, al sur por la Estructura Oropéndola, al este por la Estructura Jiquilitillo y al norte por la Estructura Peach-Colorado. Los vestigios de estos últimos dos son algo escasos, especialmente en comparación con los primeros.

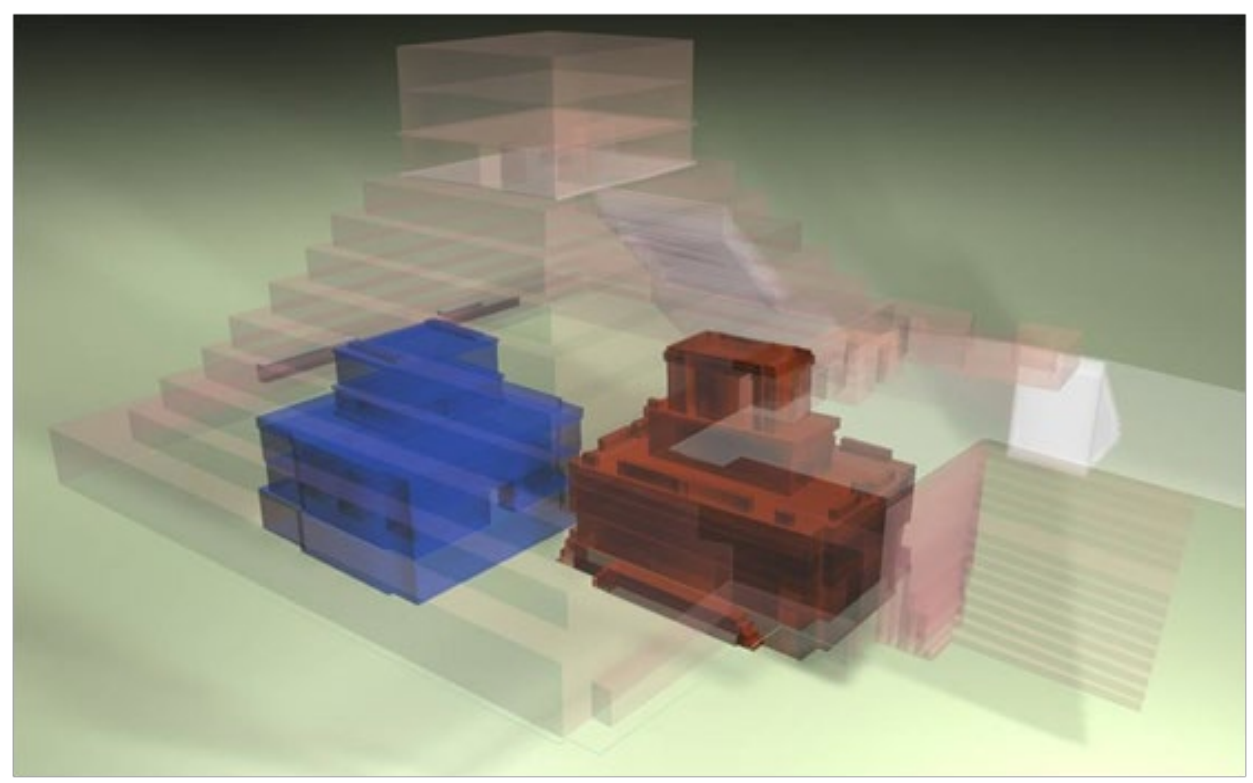

Figura 4. Rosalila (en rojo) y Oropéndola (en azul) adentro de la Estructura 10L-16 (llustración: C. Gastélum) 


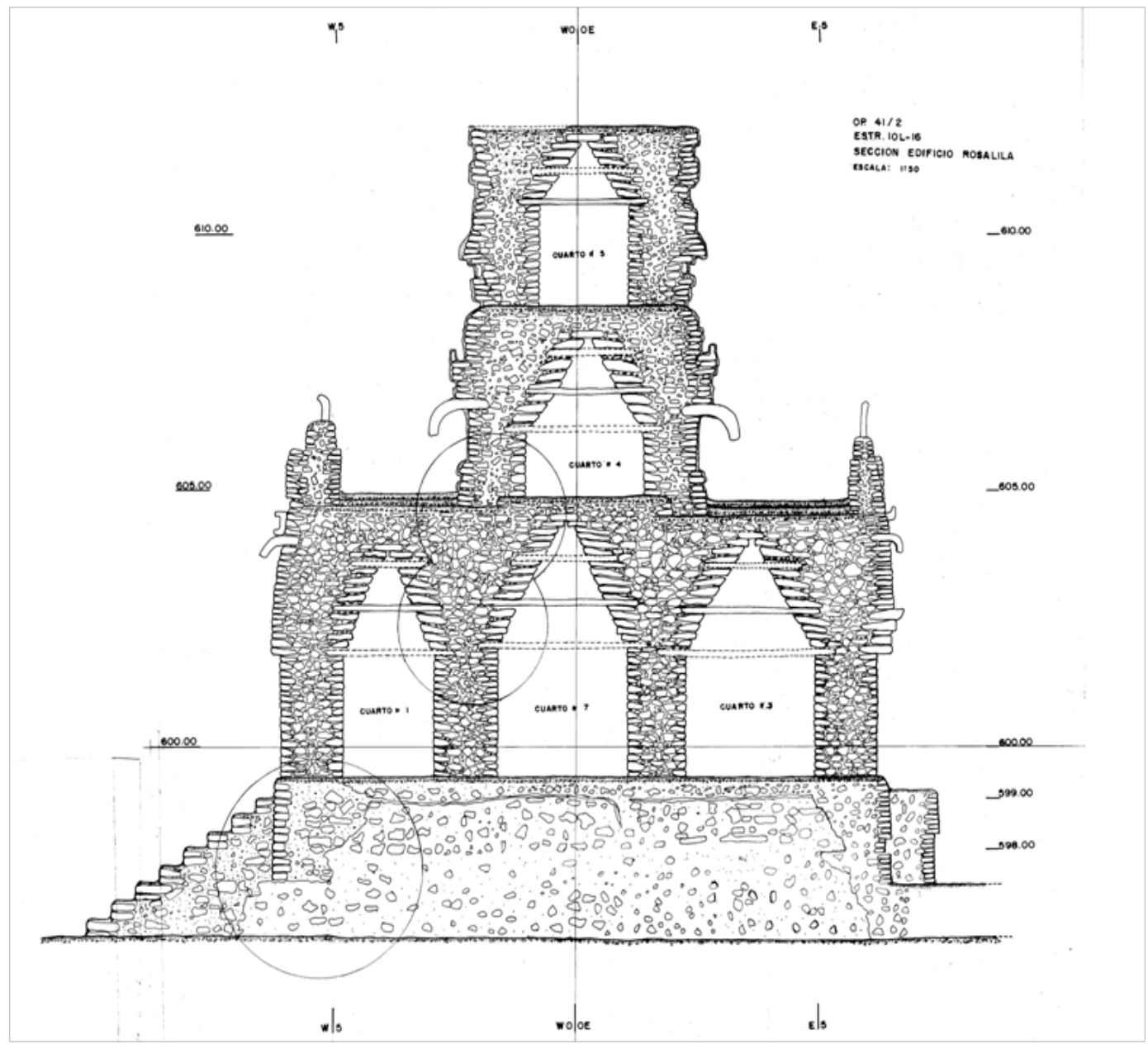

Figura 5. Sistema constructivo de Oropéndola y Rosalila

\section{DESCRIPCIÓN}

Al ser enterrada por construcciones posteriores, cerca del $25 \%$ de la estructura de Oropéndola fue destruida. Afortunadamente grandes secciones del edificio fueron conservadas, dejándonos in situ importantes elementos arquitectónicos, decorativos y evidencia histórica de su uso. Con relación a sus fachadas, adonde se preserva el principal arte escultórico del edificio, encontramos que en el primer 
nivel, el costado norte está conservado casi a la perfección, no así los otros tres, siendo el sur el más dañado y quedando pocos indicios del mismo. La situación del segundo nivel es mucho mejor: el norte y oeste están bastante completos; el este se conserva en un 50\% mientras que, como en el primer nivel, el sur está destruido.

Oropéndola se asienta sobre un elegante basamento, Oro, él cual está bastante bien conservado y mide 16.70 metros $\mathrm{N}-\mathrm{S}$, por $16.10 \mathrm{~m} \mathrm{E}-\mathrm{O}$, con una altura promedio de 2 metros. Su gradería principal está en el lado oeste, teniendo una secundaria en el norte.

Igual que todos los otros basamentos piramidales de Copán, Oro está conformado por un núcleo de tierra arcillosa (70\%) con piedra bola (cantos de río) de tamaño mediano (20 a $30 \mathrm{~cm}$. de diámetro), enchapado por muros de piedra de cantera (toba volcánica) cortados a manera de bloques con un tamaño promedio de $15 \mathrm{~cm}$ de alto, $20 \mathrm{~cm}$ de ancho y $30 \mathrm{~cm}$ de profundidad. Estos bloques de piedra están adheridos con una mezcla (argamasa) de tierra, cal, arena y agua. Esta misma argamasa es utilizada en muchos de los otros elementos constructivos de los edificios, incluyendo las graderías y paredes. Para el acabado, los muros eran revestidos con estuco (masa de cal, arena y agua) y luego pintados, siendo el rojo el más utilizado, proviniendo de tierra con un alto contenido de óxidos de hierro.

Originalmente se levantaron sobre este basamento tres niveles, en la actualidad solo se conservan significativamente los dos primeros. En el caso del tercero apenas tenemos el arranque del mismo sobre el segundo nivel del edificio. El primer nivel tiene unas dimensiones de 16.3 metros N-S por 15.7 metros E-O y una altura de 5.5 metros. Este contiene cuatro cuartos. El segundo nivel tiene 7.0 metros N-S por 9.1 metros E-O y una altura de 4.0 metros y solo tiene un cuarto. Igual que en el caso de la Estructura Rosalila, no encontramos un acceso interno o externo entre los dos niveles, por lo cual estimamos que la función principal del segundo nivel era decorativa, conformando así la mayor parte de la crestería ornamental del edificio.

De las cuatro recamaras del primer nivel, tres (las del norte, centro y sur) tienen sus ejes de este a oeste, mientras que la restante (oeste) corre perpendicular a estas. Estos recintos son rectangulares y tienen un tamaño en promedio de 10.3 por 2.6 metros con una altura de $4.7 \mathrm{~m}$. Tanto el cuarto oeste como los del norte y sur tienen puertas que dan al exterior, mientras que internamente, otra comunica al cuarto norte con el central. Estas recámaras son muy altas y angostas, abovedadas con el "arco falso" de los mayas. Las paredes están repelladas con estuco y fueron decoradas con pintura roja. 
Las puertas del primer nivel promedian $2.3 \mathrm{~m}$ de ancho y $2.4 \mathrm{~m}$ de alto. En su momento tuvieron dinteles de madera, cada uno compuestos de seis a siete tablones rústicos con un grosor en promedio de $15 \mathrm{~cm}$ y un ancho de 15 a $20 \mathrm{~cm}$. A lo largo de la recámara y en sentido transversal se utilizaban tres hiladas de vigas de amarre. Estas consistían de madera rolliza, con un diámetro de 8 a $10 \mathrm{~cm}$, empotrada en las paredes de la bóveda.

Las paredes de las recámaras son bastante gruesas $(1.5$ a $2.5 \mathrm{~m})$ y consisten de un núcleo de argamasa (40\%) con toba rústica (60\%), enchapado por bloques de la misma piedra. Para crear la bóveda, los mayas utilizaban bloques de toba alargados, con espigas de hasta un metro de largo, los cuales iban sobresaliendo escalonadamente con cada hilada que iban colocando. El cierre era creado por una última hilada de grandes bloques de toba descansando sobre las paredes. Los techos eran acabados y sellados con lozas construidas con una capa bastante gruesa $(5$ a $10 \mathrm{~cm}$ ) de estuco sobrepuesto sobre una capa de igual espesor de cascajo o grava de toba.

Cabe destacar que Oropéndola tiene un sistema constructivo y dimensiones muy similares a las de Rosalila (figuras 5 y 15 ; en planta, Oropéndola es $9 \%$ más grande). Igualmente su distribución de cuartos y niveles son similares, contando ambos con tres niveles, de los cuales los dos superiores conformaban la cresta del edificio.

\section{Fechamiento}

La construcción del edificio está fechada para mediados del Clásico Temprano. Uno de los parámetros para definir esto es la secuencia estratigráfica de pisos y construcciones entre Oropéndola, Rosalila, y otras edificaciones de la Acrópolis temprana. Esta indica que Oropéndola es un poco más tardía que Rosalila sugiriéndose una fecha entre el 550 y 600 d.C. Las fechas de radio carbono del dintel de madera de la entrada al cuarto del segundo nivel (Muestras M-07-045 y M-07-047; 530-610 d.C.) confirman este alcance temporal. El análisis de la cerámica proveniente del relleno de Oro indica que este basamento y su edificio fueron construidos durante el Clásico Temprano (Complejo Cerámico Acbi, 400625 d.C.; Viel 2006) antes del 625 d.C. Lo más seguro es que fue construida por el mismo gobernante que hizo a Rosalila, siendo éste el octavo en la secuencia dinástica, Wil Ohl K'inich, cuyo reinado termina en el 551 d.C. A su vez la cerámica de los rellenos de los cuartos de Oropéndola nos indican que esta fue enterrada durante el Clásico Tardío (Complejo Cerámico Coner, 625-830 d.C.; Viel 2006). Quizás en fechas próximas al enterramiento de Rosalila que ocurre entre el 710 y 
el 775 d.C. (Agurcia Fasquelle, Sheets \& Taube 2016) lo cual es apoyado por una fecha en radiocarbono (Muestra M-07-121; 780-880 d.C.).

Otro elemento que nos da la pauta de fechamiento más tardío que Rosalila es la decoración. Oropéndola tiene un elaborado sistema de ornamentación conformado por bloques de toba en mosaicos con pronunciados bajorrelieves que daban realce y profundidad a los mascarones vistos a la distancia (figura 6). Oropéndola tiene la característica de ser el primero de los edificios en Copán en cambiar el estilo de decoración del estuco modelado al mosaico en piedra (Pérez 2002), que en los siglos venideros se convierten en el sello distintivo de Copán como uno de los centros urbanos mejor decorados y artísticos del Mundo Maya. La connotada estudiosa del arte maya, Bárbara Fash ha notado en diferentes publicaciones (Fash, BW 1992, 2011), que la mayor cantidad de escultura tallada, que tanto renombre ha dado a la ciudad de Copán, no está representada por las estelas y altares sino que por aquella en las fachadas de los edificios.

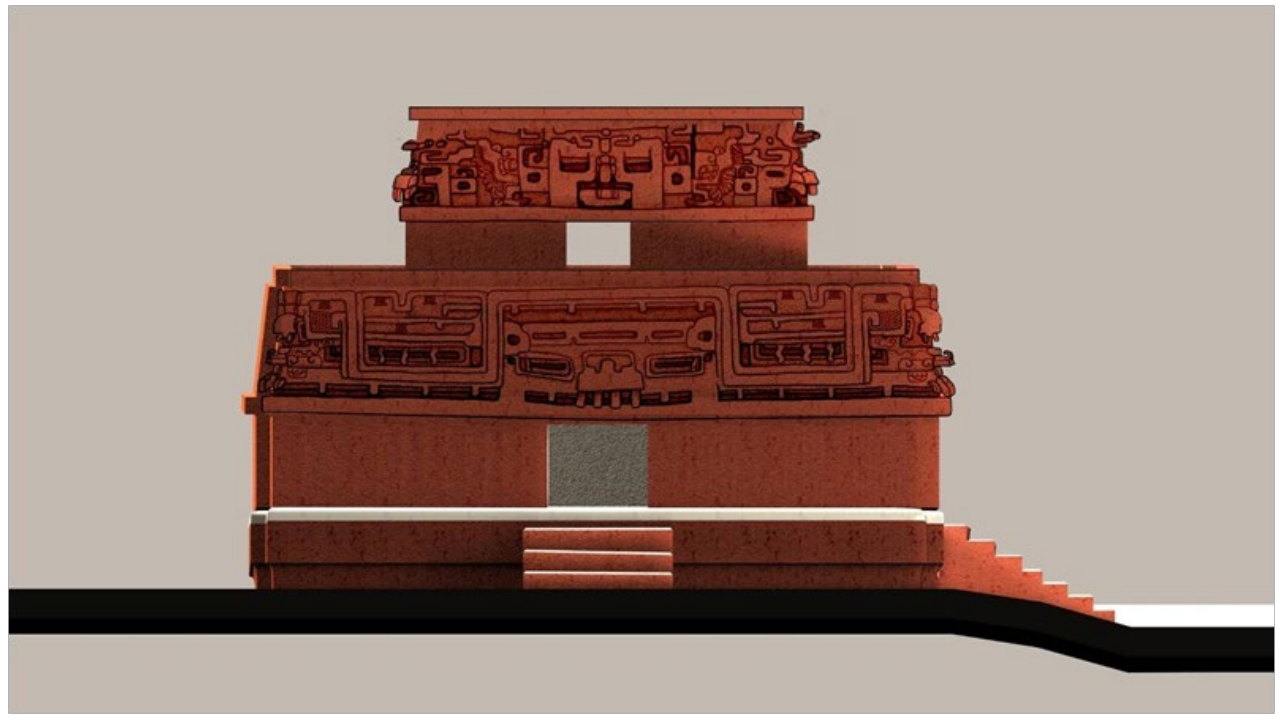

Figura 6. La Fachada Norte de Oropéndola.

(llustración: C. Gastélum, A. L. Gastélum, y J. P. Baron).

\section{Iconografía}

En las secciones del edificio que han sobrevivido hay excelentes ejemplos de los imponentes mascarones tallados en piedra que lo decoraban. En el costado norte 
del primer nivel, arriba de la moldura medianera, hay un enorme friso de 16.2 metros de largo y hasta 2.60 metros de altura (figura 7). La figura predominante aquí es el monstruo de la montaña (witz) cuyos enormes ojos llegan a tener pupilas de dos metros de largo. Al centro del friso, aparentemente saliendo de las fauces del witz, reluce el semblante de un gran felino, probablemente un jaguar (balam). Este llega a tener 5.15 metros de largo. En las esquina habían otras figuras zoomorfas, sin embargo estas están demasiado deterioradas para identificarlas con seguridad.

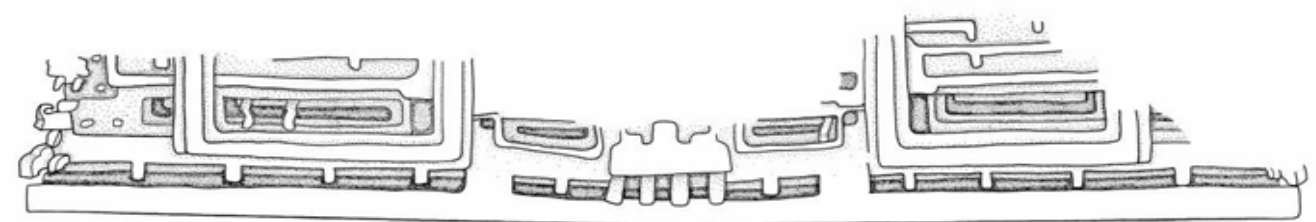

Figura 7. La Fachada Norte de Oropéndola en su Primer nivel (llustración: J. P. Baron)

Debajo de la moldura en los cuatro costados del primer nivel, había unos pequeños nichos 1.50 de largo por 0.65 de alto, los cuales aparentemente contenían escenas modeladas en estuco, guardando así relación con la tradición ancestral reflejada, por ejemplo, en Rosalila. En la fachada oeste se localizó el mejor ejemplar de estos adonde se pueden observar los restos de una figura arrodillada con un enorme cuchillo frente a él (figura 8). Este podría ser el retrato del personaje enterrado directamente debajo del cuarto central de Oropéndola en la Tumba 08-01descubierta en el 2008.

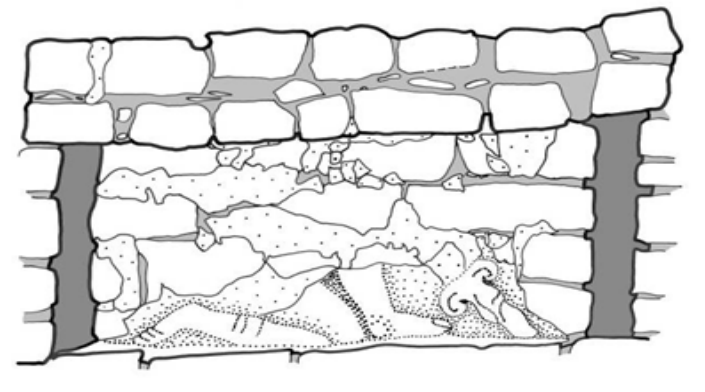

Figura 8. La Fachada Oeste de Oropéndola en su Primer nivel. (llustración: J. P. Baron). 
La iconografía del segundo nivel del edificio está aun mejor conservada que la del primero. Los vestigios encontrados por nuestras excavaciones indican que, al igual que Rosalila, las fachadas en lados opuestos del edificio eran idénticas. De esta manera la este y oeste son iguales entre si, así como las norte y sur. Los frisos decorativos miden 7.00 en el caso de los primeros y 9.20 en los otros. La altura máxima en que se conservan es de 2.40 sobre la moldura medianera.

En todas las esquinas de este nivel de Oropéndola se detectaron otros mascarones de enormes felinos, que para nosotros deben ser jaguares, con un tamaño promedio de 1.60 por lado. Estos tienen sus amenazantes fauces entreabiertas con sus hocicos y colmillos proyectándose más allá de las esquinas. El jaguar también domina el centro del edificio en los costados oriente y poniente adonde su rostro llega a medir 3.50 metros de largo (figura 9).

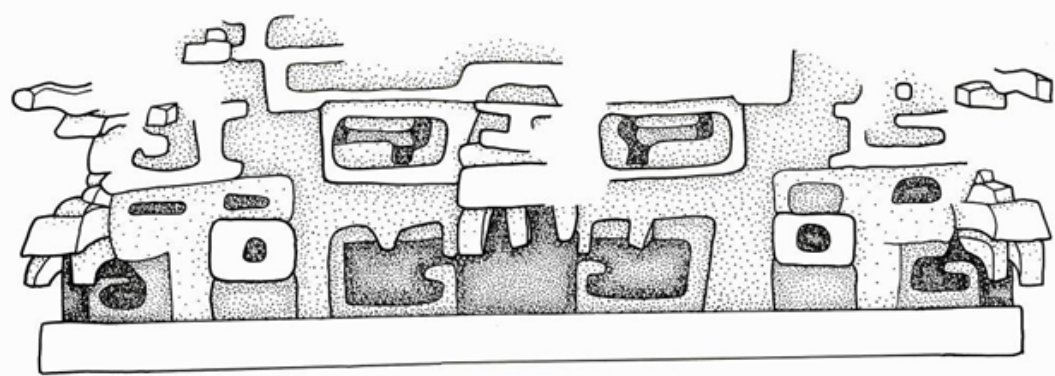

Figura 9. La Fachada Oeste de Oropéndola en su Segundo Nivel.

(llustración: J. P. Baron).

Al centro de la fachada norte encontramos la representación de un ave cuyo pico se proyecta como un gancho sobre la pequeña y única puerta del segundo nivel. Este mascaron mide 9.20 de largo, incluyendo sus elegantes orejeras. Contiguo a esta ave aparecen las cabezas en perfil de unos reptiles con sus fauces entreabiertas, que dan paso a los jaguares antes descritos que hay en las esquinas (figuras $10 \mathrm{y}$ 11). 


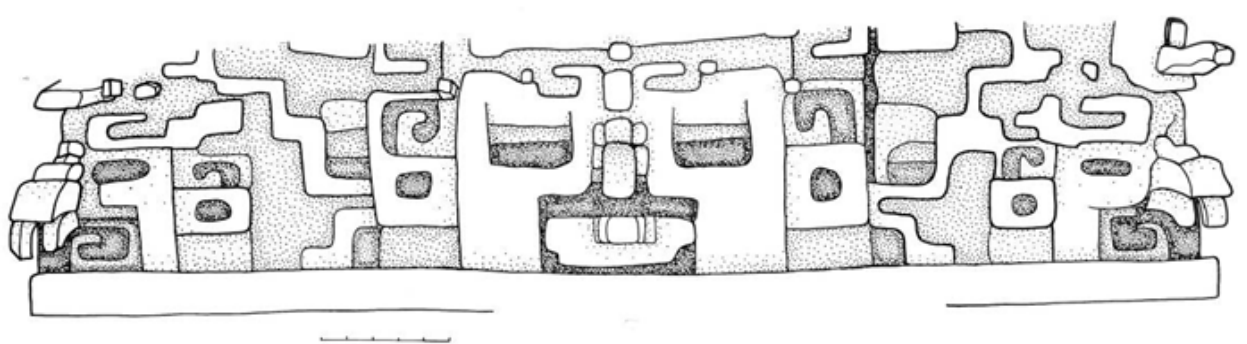

Figura 10. La Fachada Norte de Oropéndola en su Segundo Nivel. (llustración: J. P. Baron).

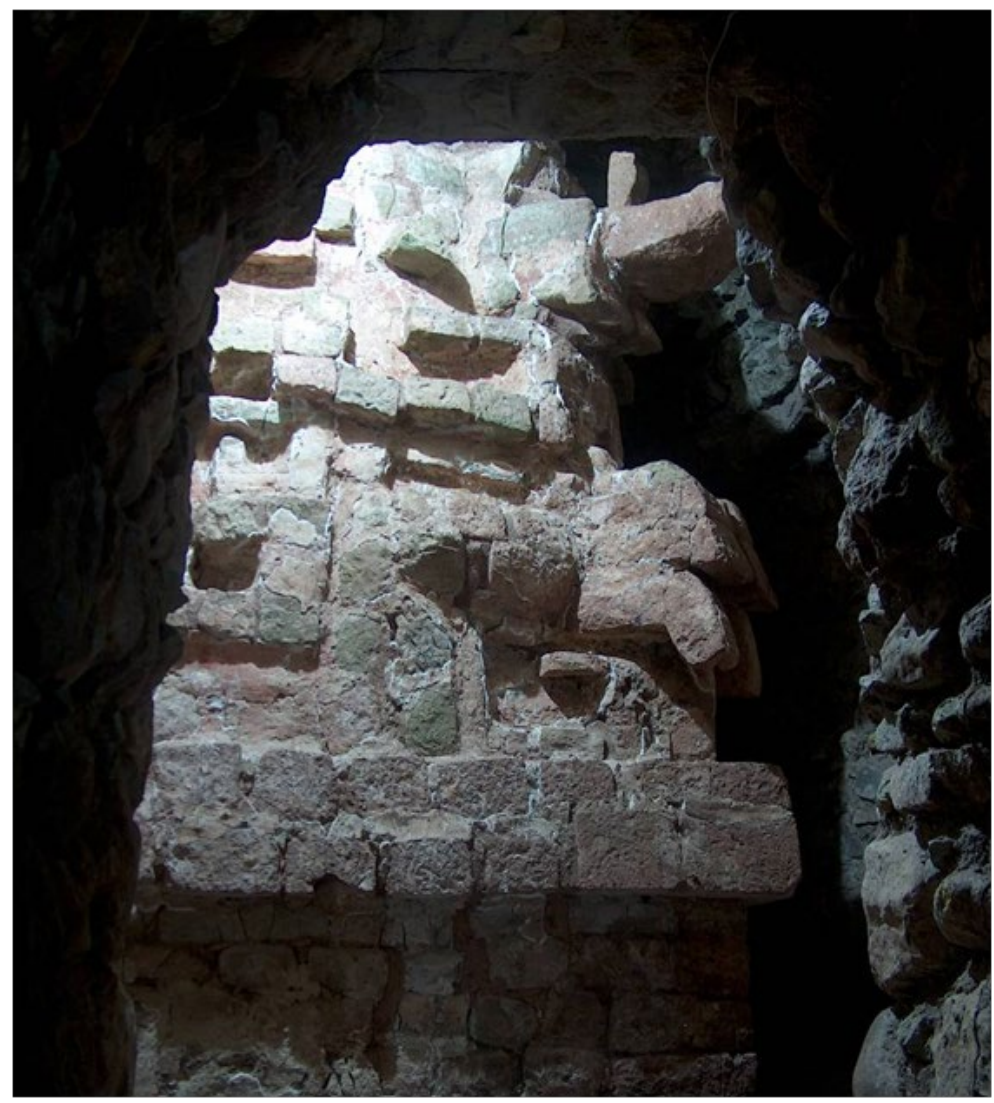

Figura 11. Jaguar en la Esquina Noroeste del Segundo Nivel de Oropéndola (Foto: J. C. Pérez) 


\section{Interpretación}

Como se ha observado repetidamente en Copán, la iconografía de las edificaciones tenía una significación particular que se relacionaba con los actores sociales de su entorno. Las construcciones monumentales y su arte eran el reflejo del poder económico y social de los gobernantes al mismo tiempo que eran portadoras de un sistema ideológico que reflejaba la visión del mundo y del universo que tenían los mayas antiguos. Las estructuras monumentales eran el lugar donde se asentaba y reflejaba el poder ideológico y político (Miller 1986, Schele y Miller 1986, B. Fash 1992, Fash y Agurcia 1996, W. Fash 2001, Taube 2004a y 2004b).

Los impresionantes mosaicos de escultura en piedra, a partir de Oropéndola dejan atrás los espléndidos tiempos del estuco modelado y abren el camino al nuevo género decorativo que a corto plazo llegará a dominar las fachadas de los edificios de Copán. Tanto su iconografía como su ubicación en el costado sur de la parte alta de la antigua Acrópolis muestran una clara relación del edificio con el inframundo. La imagen que prevalece es la del jaguar, animal que se asocia en el arte maya con el sol nocturno, la noche, las tinieblas, y el ámbito acuático del inframundo. Las imágenes no sólo son formas artísticas, sino que representan todo un sistema de creencias de lo que se considera fuerte, valiente y poderoso, tanto en el mundo real (el gobernante y sus guerreros) como en el supernatural (al rey de los cielos, el Señor Sol, K'inich Ahau o Ahau Kin, en su aspecto nocturno, frecuentemente llamado "jaguar del inframundo") (Schele y Miller 1986: 50, Miller y Taube 1993:102104, Taube 2016, Valverde 2004).

Asimismo en Copán como en otros sitios mayas, el jaguar no solo aparece como imagen sino que como atuendo de los reyes en la forma de pieles, cráneos, mandíbulas, garras, y colmillos que cubría o acompañaban sus cuerpos, camas, tronos y entierros. Singular entre estas está la ofrenda de por lo menos 16 felinos en una fosa localizada entre el altar Q y el Templo 16 a corta distancia de Oropéndola y Rosalila (Ballinger et al 2000, W. Fash 2001:170, Sugiyama y Fashn.d.).

En las representaciones mayas se le vincula, como ya se mencionó, con el sol nocturno, representándose como deidad solar pero con rasgos de felino. El sol, al penetrar al inframundo en cada atardecer, adquiere todos los atributos del jaguar como se puede ver en el arte del Patio Oriental de la Acrópolis. El jaguar además, guarda un fuerte vínculo con las montañas y sus cuevas por lo cual luce sumamente apropiado esta conjugación en el friso norte del primer nivel de Oropéndola adonde se marca al edificio como la montaña sagrada del jaguar (balam witz). En los 
murales de San Bartolo, Guatemala, hay una escena muy realista que permite apreciar esta relación muy especial entre el jaguar y la preciosa Montaña de la Flor del cosmos Maya (Saturno et al 2005:13-21).

El felino fue transformado en enunciados culturales y entretejido con la política y la religión. Utilizado como una política de legitimación, estuvo siempre asociado con aspectos como la gobernación hereditaria, la guerra y el sacrificio humano. Valverde (2004) también indica que además de estar asociado al poder político y a prácticas shamánicas, se le vincula con el espacio nocturno e infra terrestre, la agricultura, fertilidad, destrucción y muerte.

El gran mascarón de ave que está al centro de la fachada norte en el segundo nivel de Oropéndola bien podría ser el Principal Dios Pájaro (también conocido como Pájaro celestial o Pájaro-serpiente). A éste se la ha asociado con Vucub Caquix del Popol Vuh en la época colonial e Itzam-Yeh del Periodo Clásico (Freidel et al. 1993:70). El Principal Dios Pájaro es de naturaleza celestial y frecuentemente es asociado con las bandas planetarias o con la cúspide del árbol axis mundi. Numerosos estudiosos piensan que es un aspecto de Itzamná (dios D), deidad suprema (Hellmuth 1987:365; Miller y Taube 1993:100; Taube 1992:40; De La Garza 1995: 16-18). Karl Taube (1992:148; Taube et al 2010) también lo asocia con el dios del sol y el dios del maíz. De igual manera y en consonancia con el jaguar de Oropéndola, otros distinguidos estudiosos lo vinculan con la realeza y la ubicación del rey en el cosmos (Cortez 1986:90; Baudez 1995).

Esta iconografía nos permite postular a Oropéndola como el Templo del Jaguar, del Dios Sol del Inframundo. Sus puertas eran accesos al inframundo, mientras que su cuarto central era un recinto sagrado, una cueva dentro de la montaña sagrada, adonde el gobernante de turno podía comulgar con sus ancestros y particularmente con el personaje que estaba enterrado en la Tumba 08-01, descubierta en 2008. Aunque hasta el momento no hemos podido descifrar una conexión mas directa entre los elementos iconográficos del edificio y el nombre especifico de un solo gobernante Copaneco, no perdemos esperanza de poder hacerlo mas adelante.

\section{Ofrendas y Grafiti}

A diferencia de Rosalila, los cuartos de Oropéndola carecían de artefactos in situ sobre los pisos, dando la impresión de que estos hubieran sido barridos antes de ser cancelados, rellenados y enterrados. A pesar de que no se encontraron ofrendas de este tipo, el edificio si contó con una importante serie de ofrendas 
colocadas originalmente en los ejes centrales de los cuartos debajo de los pisos. En las excavaciones solamente localizamos los agujeros de estos que, en algunos casos, contaban con restos de huesos quemados, fragmentos de conchas y carbón. Es evidente que en su momento aquí hubo depósitos especiales que luego fueron removidos.

Una excepción fue la Ofrenda 07-02, localizada bajo la banca del cuarto central del edificio, la cual tuvo una conformación cuadripartita, donde en cada punto cardinal se colocó un objeto, en su mayoría de jade. Asimismo en el centro había otra. La más destacada estuvo en el costado este del deposito y consistía de una figurilla antropomorfa de $10.3 \mathrm{~cm}$ de alto, $6.4 \mathrm{~cm}$ ancho y $2.0 \mathrm{~cm}$ de espesor. Se trata de un "jorobado" con la vista hacia el norte. Presenta las dos piernas flexionadas y sus manos se localizan frente al torso. Físicamente la figura humana tiene labios muy gruesos, frente con deformación craneana tabular oblicua, pelo y una especie de tocado o peinado sobre su cabeza. La ofrenda al centro consistía de dos mitades de concha Spondylus sp. con una esfera de jade de 6.9 de diámetro y 4.9 de altura entre ellas. Debajo de estos artefactos mayores se detectaron huesos quemados de animales, restos de minerales, semillas, flores y otras fibras, así como una diminuta cuenta de concha (figuras 12 y 13).

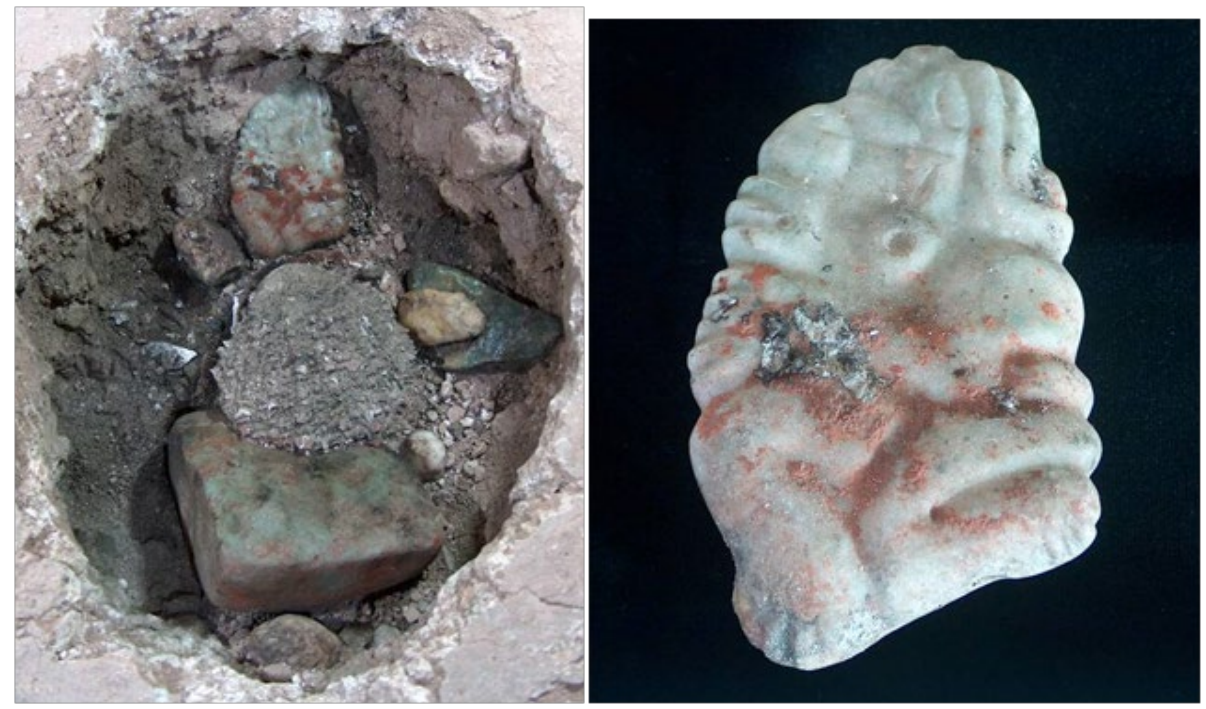

Figura 12. Ofrenda 07-02 del Cuarto Central de Oropéndola

(Fotos: J. C. Pérez) 


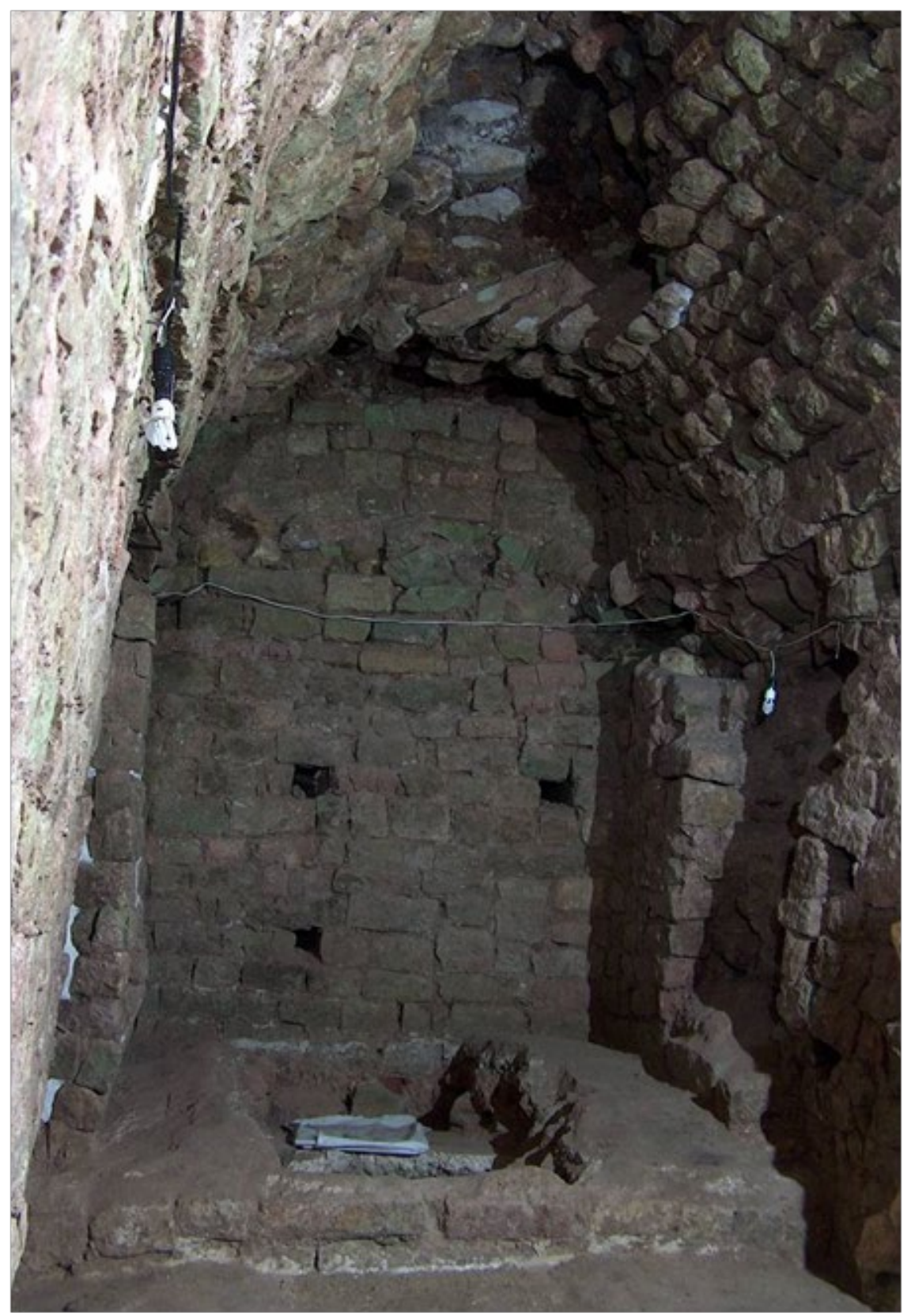

Figura 13. El Cuarto Central de Oropéndola. (Foto: J. C. Pérez). 
En igual forma que en Rosalila, sobre el piso del cuarto de la cresta se detectaron unos tableros de patollis grabados en el estuco. Sin embargo habían muchos más de estos en Oropéndola ( 9 vs. 2) así como una serie de otros elementos antropomórficos (figura 14; Zralka 2014:152 figura 5.29).

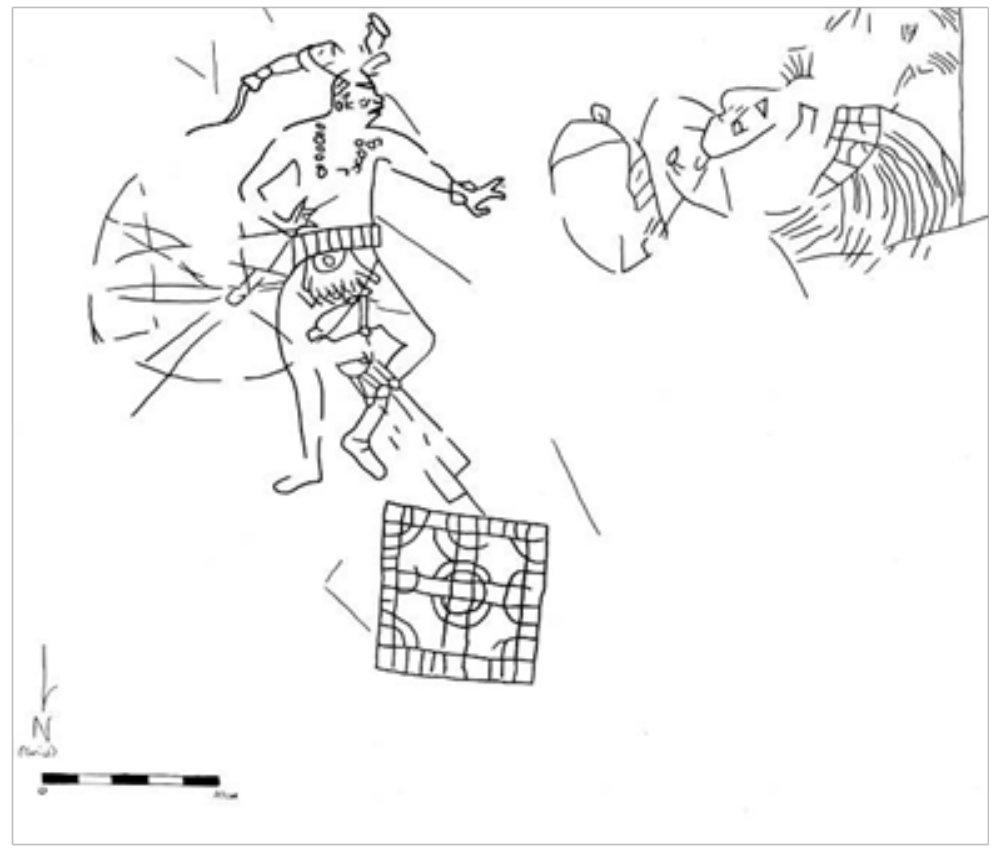

Figura 14. Grafiti del Segundo Nivel de Oropéndola. (llustración: J. P. Baron). 


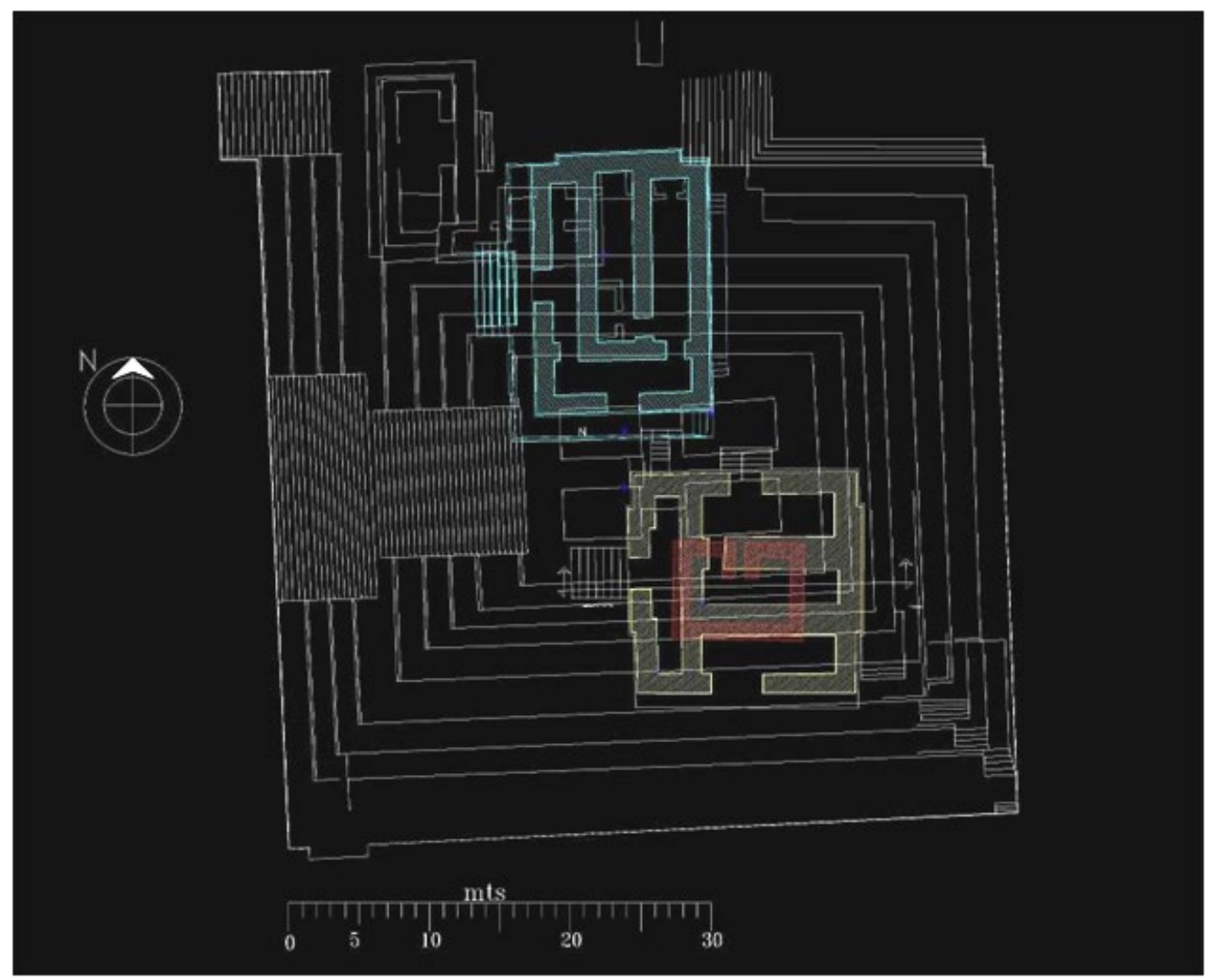

Figura 15. Rosalila (en azul) y Oropéndola (en amarillo y rojo) bajo la Estructura 10L-16 (llustración: T. Medina)

\section{Tumba 08-01}

En diciembre de 2007 nuestras excavaciones del cuarto central de Oropéndola expusieron un alineamiento de lajas rectangulares (denominado RC-2-426), al centro del mismo que en promedio tuvieron $1 \mathrm{~m}$ de largo por 30 de ancho, 11 de los cuales formaban una hilada continua atravesando el cuarto de N-S. Contiguo a esta hilada hacia el este y descansando sobre el piso del cuarto descubrimos los residuos de una actividad con fuego entre los cuales habían fragmentos de carbón (Muestra M-07-121), madera en rajas pequeñas, semillas, huesos de animales pequeños, un fragmento de escultura, restos de estuco pintado en rojo y cerámica (RC-2-548) (figura 16). 


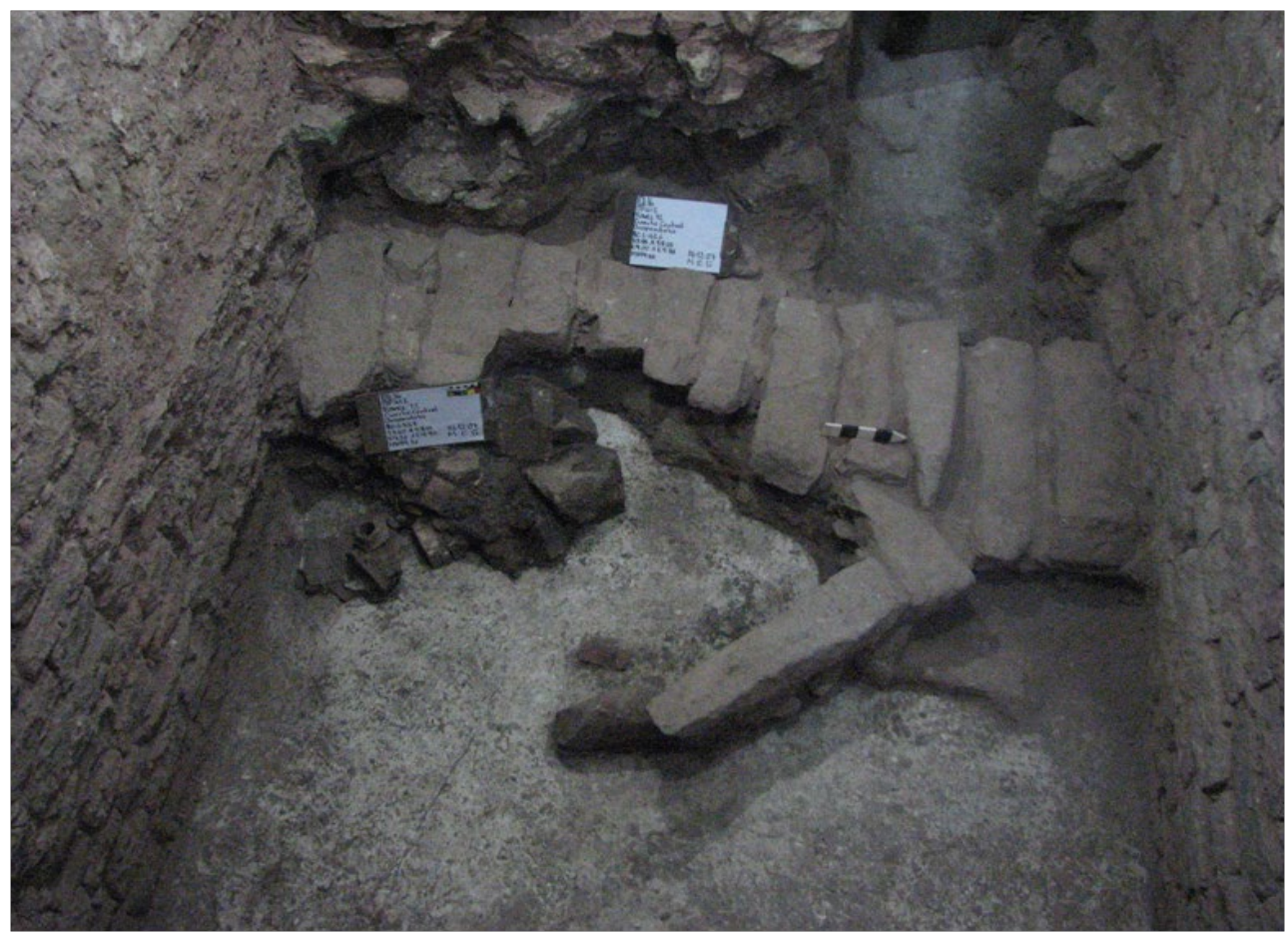

Figura 16. [Hi res] Alineamiento de lajas (RC-2-426) y restos de actividad con fuego (RC-2-548) en el Cuarto Central de Oropéndola(Foto: J. C. Pérez)

Para darle seguimiento a estos rasgos, así como para aclarar la secuencia constructiva del Basamento Oro y el Edificio Oropéndola, a principios del 2008 se inició una excavación al centro del cuarto central (Pozo S8.50 E10.80). El 25 de febrero esta excavación detecto unas lajas rectangulares enormes de toba (con un promedio de más de $1.3 \mathrm{~m}$ de largo, $55 \mathrm{~cm}$ de ancho y $30 \mathrm{~cm}$ de profundidad) a 2.40 metros debajo del piso del cuarto. A estas se les asignó el número de rasgo RC-2-561 (figura 17). Lamentablemente este descubrimiento ocurrió al final del proyecto bajo ejecución (PDRVC) por lo que no se pudo investigar sino que hasta el inicio de otro proyecto (Proyecto Oropéndola). 


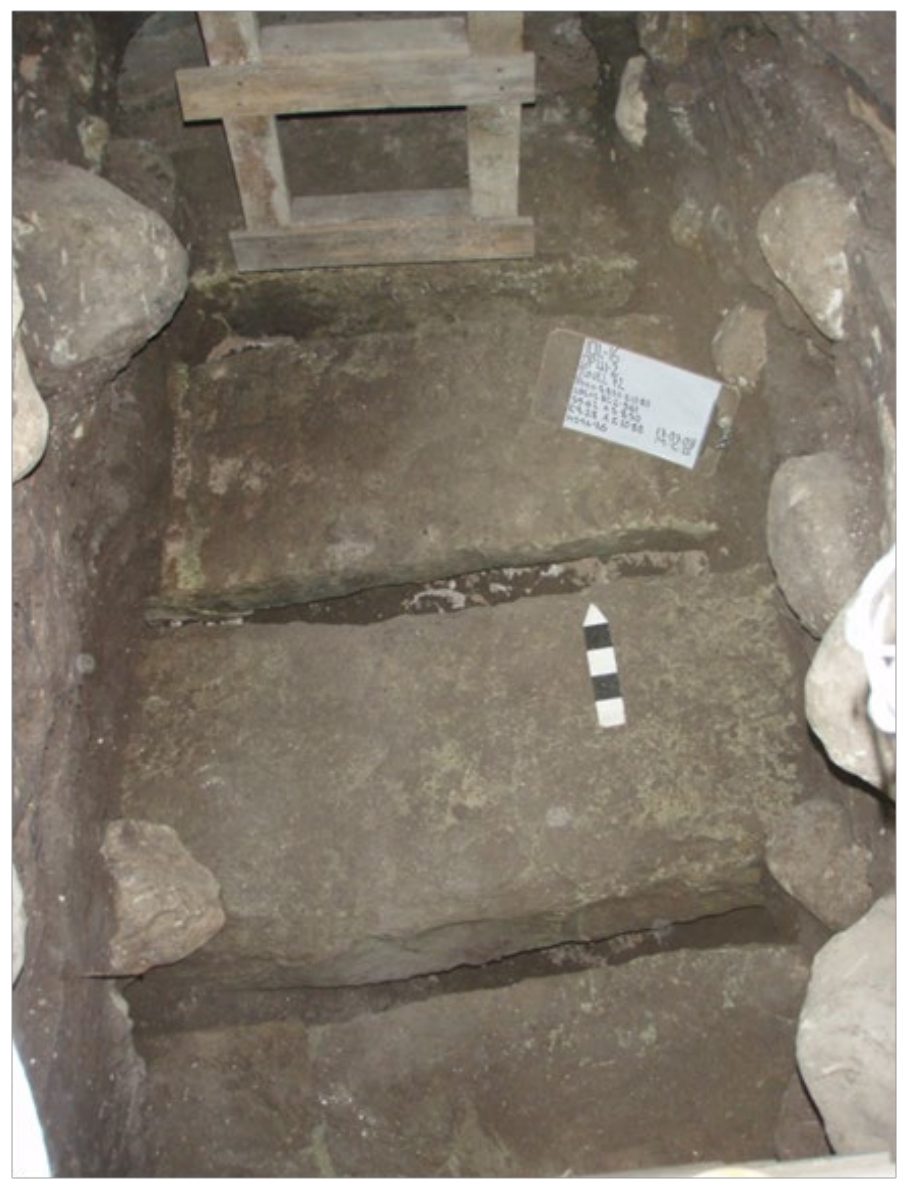

Figura 17. Alineamiento de lajas rectangulares muy grandes. (RC-2-561) (Foto: J. C. Pérez).

A finales del mes Septiembre del 2008, y tras de bajar dos metros debajo del alineamiento de grandes bloques de piedra conocido como el RC-2-561, se pudo notar la presencia de unas paredes de piedra. Poco después se pudo confirmar que estas formaban parte de un recinto funerario (Tumba 08-01) con atributos reales. Este es rectangular y mide 1.30 de alto, 1.75 de norte a sur y 1.40 de este a oeste (figura 18). Lastimosamente, el techo de la recamara colapsó en tiempos antiguos por lo que el recinto estaba totalmente aterrado y los restos muy dañados.

Al reconstruir la secuencia constructiva de esta tumba podemos notar lo siguiente: las enormes lajas del RC-2-561 descansaban sobre un piso estucado apodado Doña Molly (RC-2-570) el cual conforma la parte superior del Basamento Marino, 
que fue el que canceló el recinto funerario. Para crear la recamara funeraria, los mayas excavaron una fosa de casi 1.7 metros de profundidad debajo de Marino, atravesando dos basamentos máas antiguos, siendo estos el Basamento Guacaverde y luego el Basamento Mango Verde. La arquitectura de la tumba quedó comprendida principalmente dentro del úultimo de estos con las piedras de cierre a la misma altura que el piso Doña Nereyda (RC-2-575) el cual originalmente conformaba la parte superior de Mango Verde.

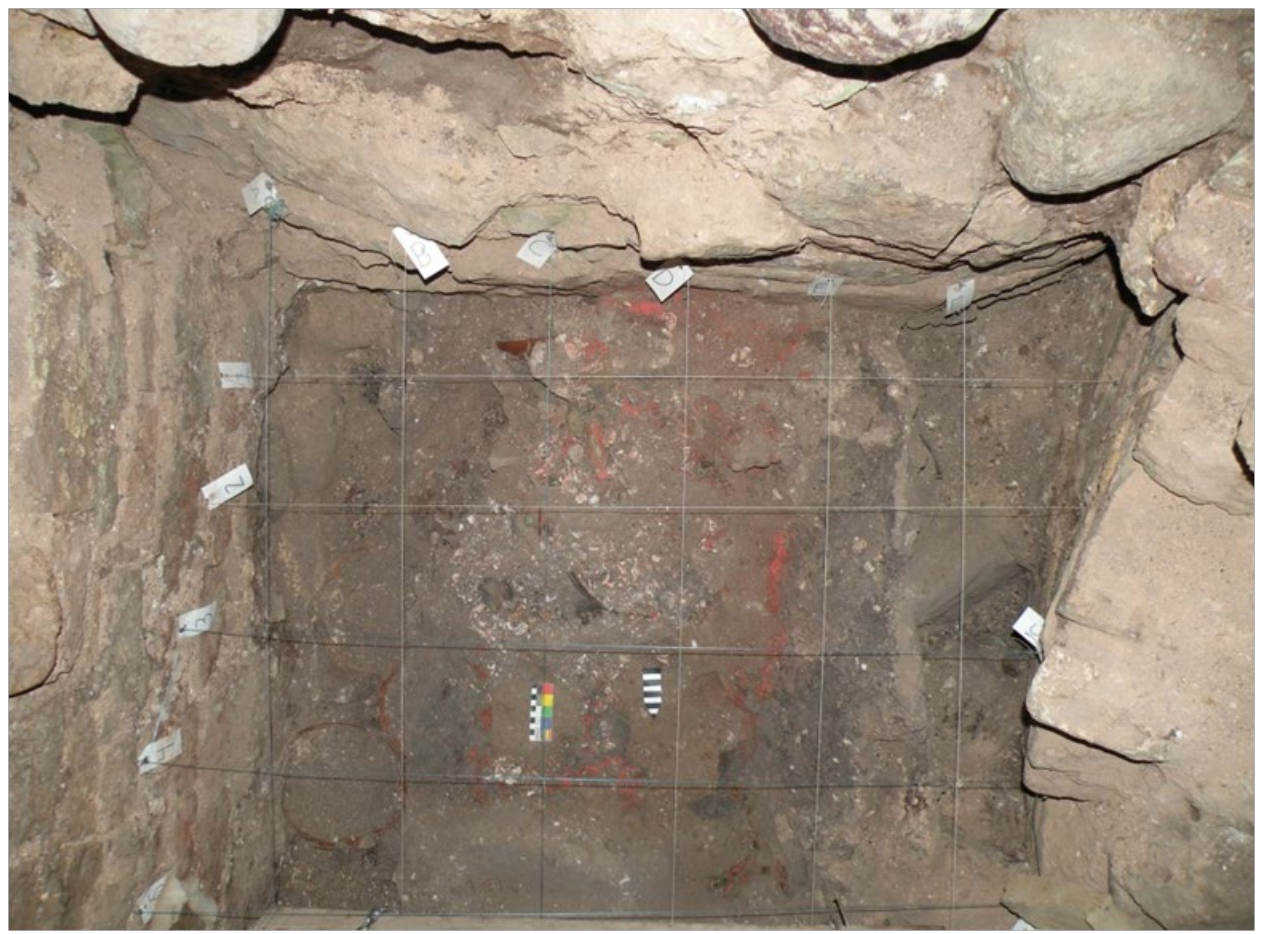

Figura 18. Recinto funerario (Tumba 08-01)

Tanto el Basamento Marino que sello el recinto funerario, como el Edificio Tz'unun que descansaba sobre este fueron severamente dañados por la construcción del Basamento Oro sobre el cual descansa Oropéndola. Sin embargo nuestras excavaciones lograron comprobar que Oro guardo el mismo tamaño y distribución espacial que su antecesor, Marino, quedando de esta forma la Tumba 08-01 también al centro de Oropéndola. 
Debido a que estas excavaciones están en los niveles más antiguos de la Acrópolis este recinto debe corresponder a la tumba de uno de los primeros reyes de la antigua ciudad. Las excavaciones y análisis preliminar de los restos materiales (especialmente de la cerámica; figura 19) indican que la Tumba 08-01 fecha entre 435 y 490 después de Cristo. En este período encontramos a los gobernantes correspondientes a las posiciones segunda a sexto de la dinastía copaneca (437524 d.C.) sobre quienes sabemos muy poco (Martin y Grube 2008; Pragner y Wagner 2008). Algunas de las fechas de radio carbono obtenidas por nuestras excavaciones indican que Marino pudo haber sido construido cerca del 430 d.C. (Muestra L1595/M-08-047). Entre tanto, las fechas obtenidas tanto del relleno de la fosa como de la tumba misma cubren un rango mas amplio, desde 20 hasta 550 d.C. (Muestras L1601/M-09-171 y L1599/M-08-053) con las fechas de dos conchas Spondylus de la tumba misma marcando una fecha más precisa entre 465-584 d.C. (Muestras Número 16/OZN-040 y 17/OZN-041).

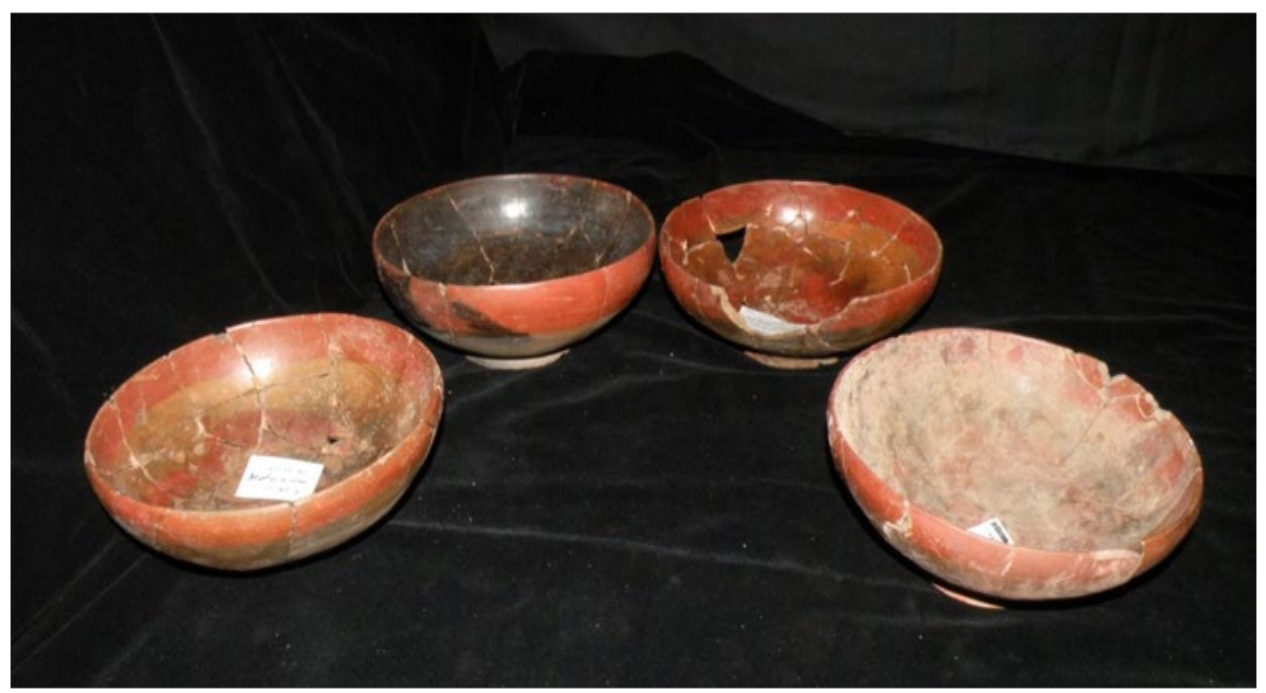

Figura 19. Cerámica de la Tumba 08-01 (Grupo Cerámico Melano)

Debido al colapso del techo y a las propiedades de la tierra en la tumba, el esqueleto estaba en muy mala condición. Ninguno de los huesos estaba completo y la mayoría se presentaba en fragmentos. Sin embargo, el cuidadoso trabajo realizado por la experta Katherine Miller permitió determinar que el esqueleto corresponde a un adulto, mayor de 30 años, con una estatura entre 154 y $167 \mathrm{cms}$. Este descansaba extendido, boca arriba (decúbito supino) y con la cabeza hacia el sur. El análisis 
químico de su dentadura (isótopos de estroncio) indica que se trata de un individuo que creció en Copán.

Como es de esperarse, al proceso de enterramiento conllevó una gran cantidad de preparativos, ceremonias, ritos y ofrendas. Muchos de los restos de estos se pierden con el pasar de los siglos, sin embargo debido al minucioso trabajo arqueológico, algunos se han podido rescatar y tendrán mucho más sentido después del análisis en laboratorio. De esta forma se sabe que el difunto, con toda su vestimenta y ornamentación, fue puesto sobre una cama de madera. Debajo de esta se pusieron cerca de dos docenas de vasijas de cerámica con alimentos y bebidas. Hay también una pareja de ollitas de mármol o alabastro. Sobre la cabeza parece haber habido un elegante penacho de plumas y conchas mientras que sobre el pecho se han detectado los restos de lo que parece ser una coraza formada por chapitas 0 pequeñas placas de concha que fueron perforadas para unirlas. Aquí también se han identificado por lo menos tres collares con cuentas de jade, concha y perla, así como cinco pares de orejeras de jade y concha. Algunos de estos objetos han sido preciosamente tallados incluyendo 4 dijes cilíndricos, un dije con el rostro del Dios del Sol (figura 20; K'inich Ahau) y otro con la carita de un monito (figura 21; ahau). Estos dos últimos representan títulos reales utilizados como distintivos por los gobernantes mayas. Asimismo hay otros objetos delicadísimos que combinan concha con jade y otros minerales, entre estos se pueden contar por lo menos tres espejos y un collar.

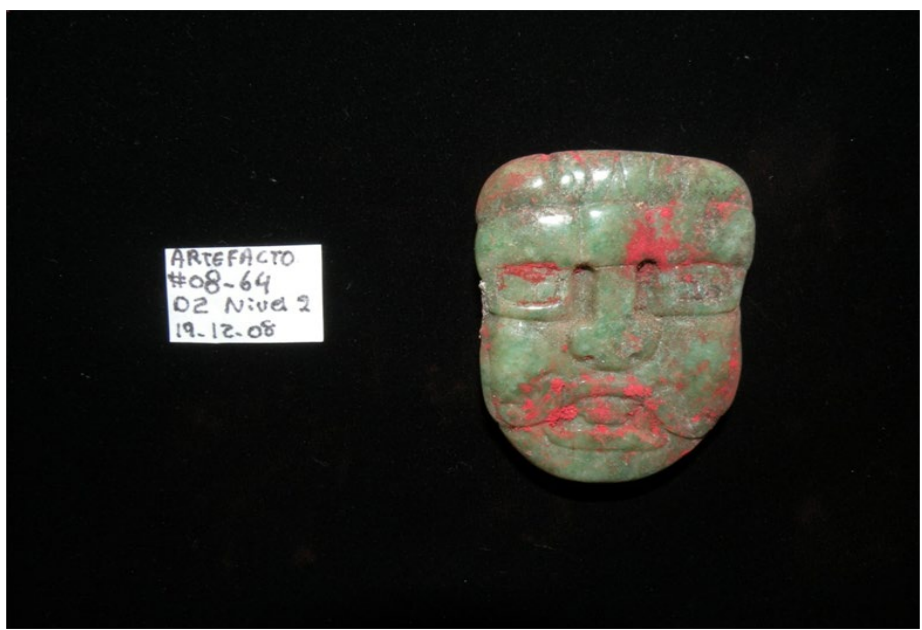

Figura 20. Cuenta de jade con imagen del Dios del Sol (K'inich Ahau) encontrada adentro de la boca del difunto. (Foto: M.E. Garza) 


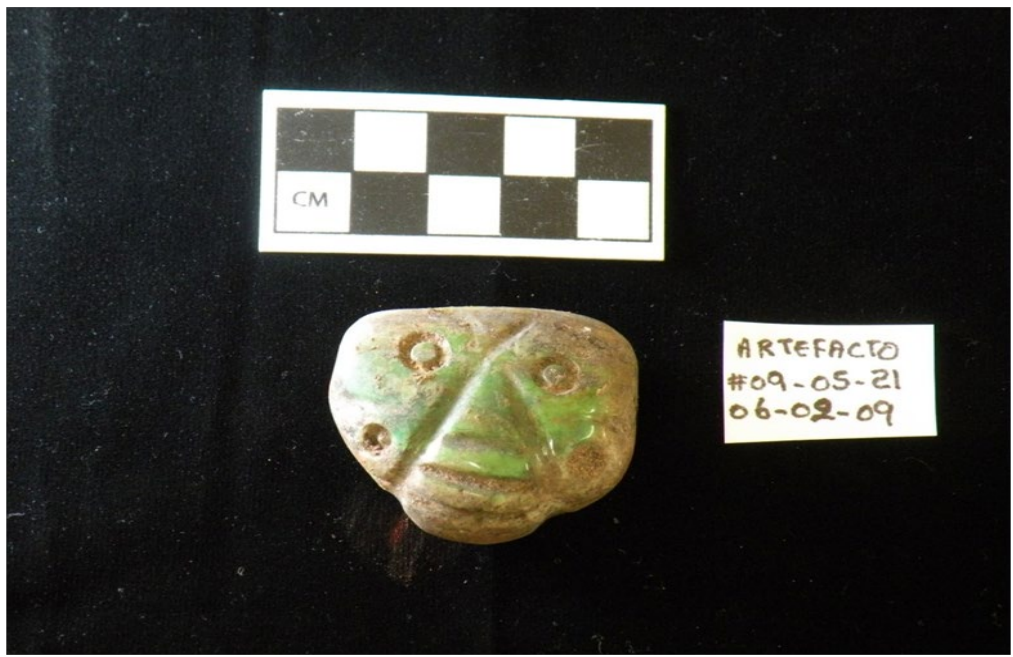

Figura 21. Cuenta de jade con imagen de un mono (Ahau). (Foto: M.E. Garza)

Otra curiosidad de esta tumba es que contiene una enorme cantidad de conchas marinas (figura 22). Dos grandes grupos de estas fueron colocadas a los pies del difunto (figura 23), mientras que otro grupo fue puesto cerca del hombro derecho. Hay también cientos de lentejuelas de obsidiana verde.

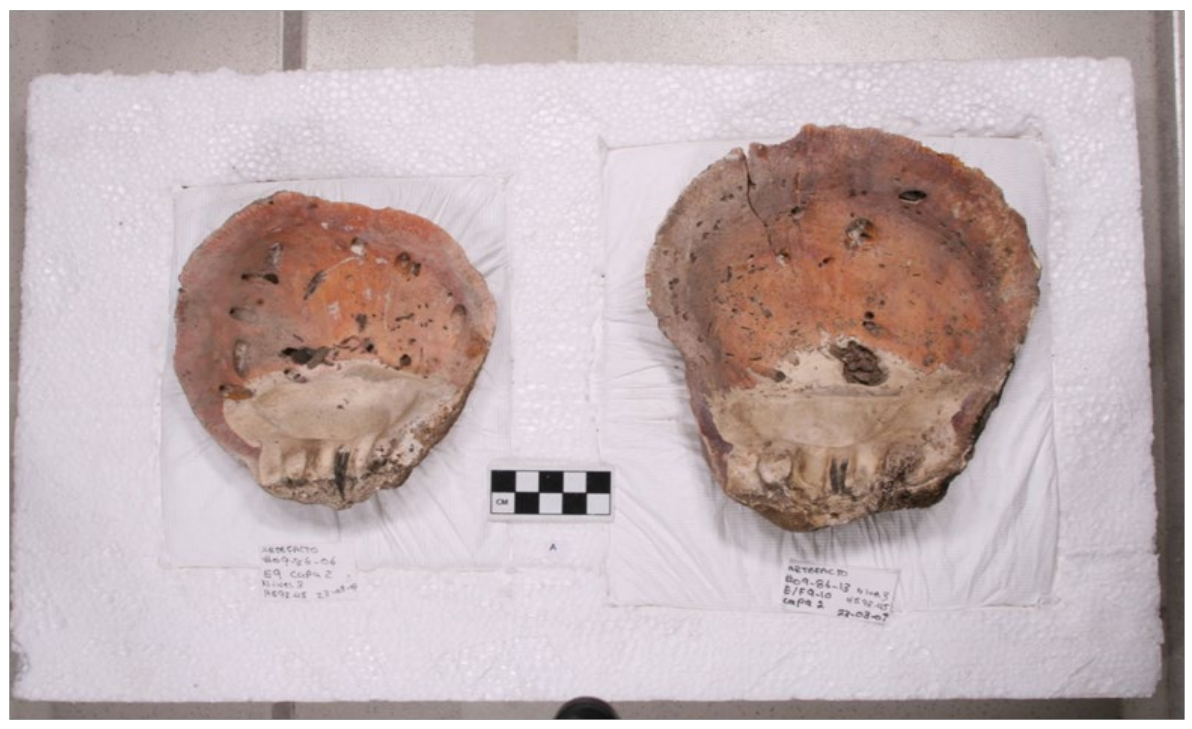

Figura 22. Conchas marinas (Spondylus sp.) (Foto: M.E. Garza) 


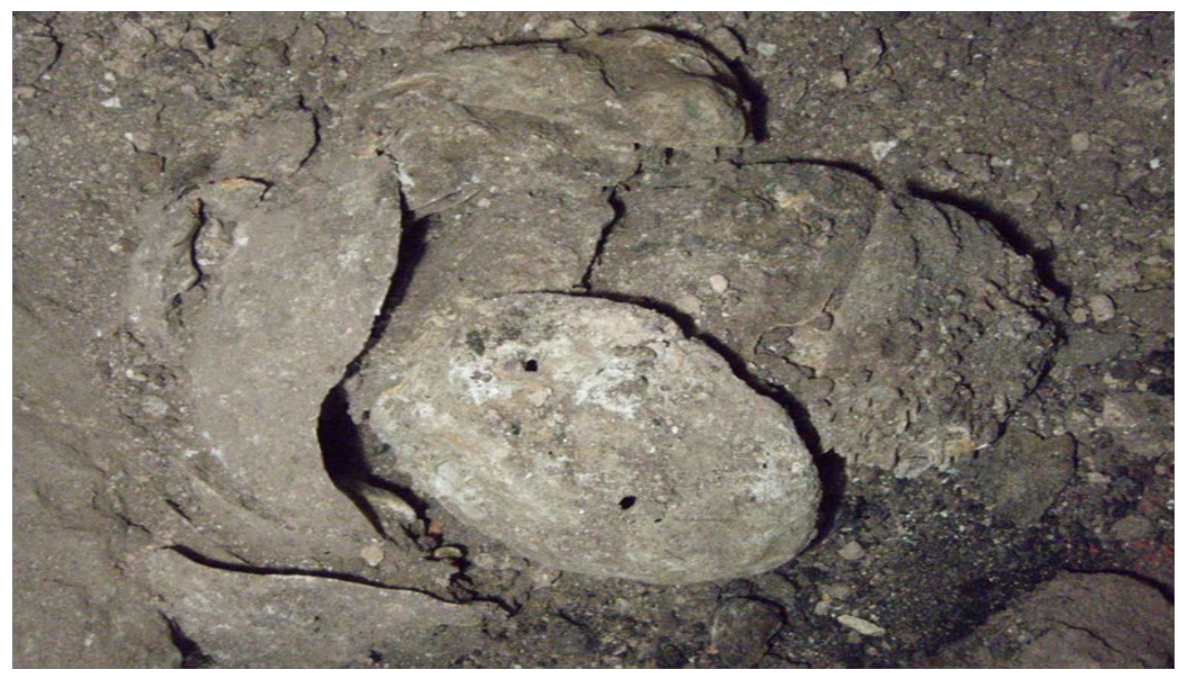

Figura 23. Bulto de conchas marinas a los pies del difunto (Spondylus sp.). (Foto: M.E. Garza).

Como es típico de Copán y otros sitios de la región sur del área Maya en el Clásico Temprano, los artefactos de la tumba demuestran una fuerte afiliación con Teotihuacán. Principal entre estos están las vasijas cilíndricastrípodes con decoraciones incisas rellenas de cinabrio (figura 24; Conides 2001:38; muy típicas también de las tumbas de Kaminaljuyú, Kidder et al 1946), los cuencos de anaranjado delgado, laminas de mica, espejos de pirita y las lentejuelas de obsidiana verde. 


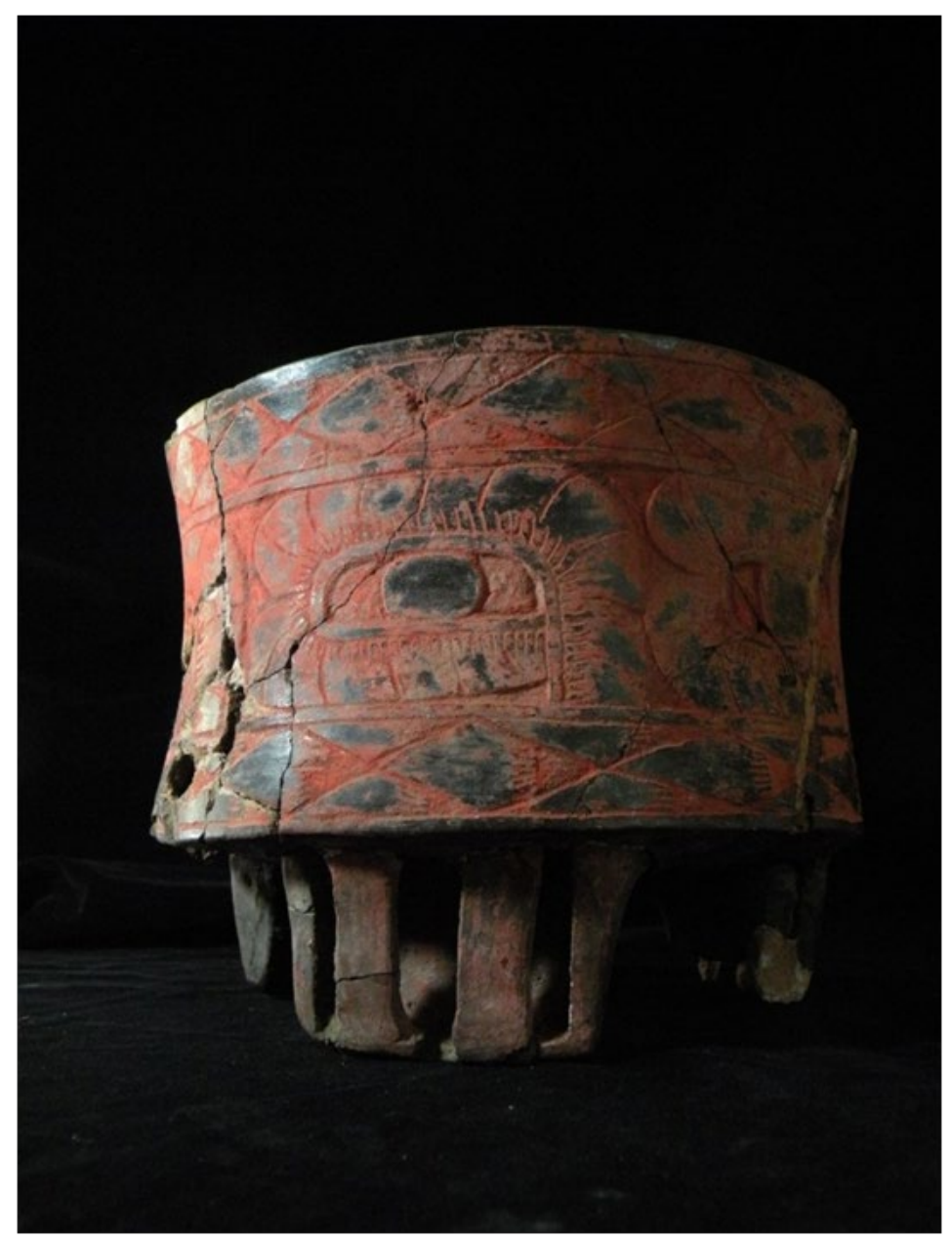

Figura 24. Vasija trípode incisa con pigmento rojo (Tipo Luisiana Inciso). (Foto: M.E. Garza)

Hay pigmento rojo en casi todas las partes de la tumba (figura 25). Este es de origen mineral y lo más probable es que sea cinabrio. Muchos de los vestigios de las envolturas, vestimentas y otros objetos perecederos (madera, cestas, pieles, petates, etc.) tan solo se conservan como manchas en la tierra. 


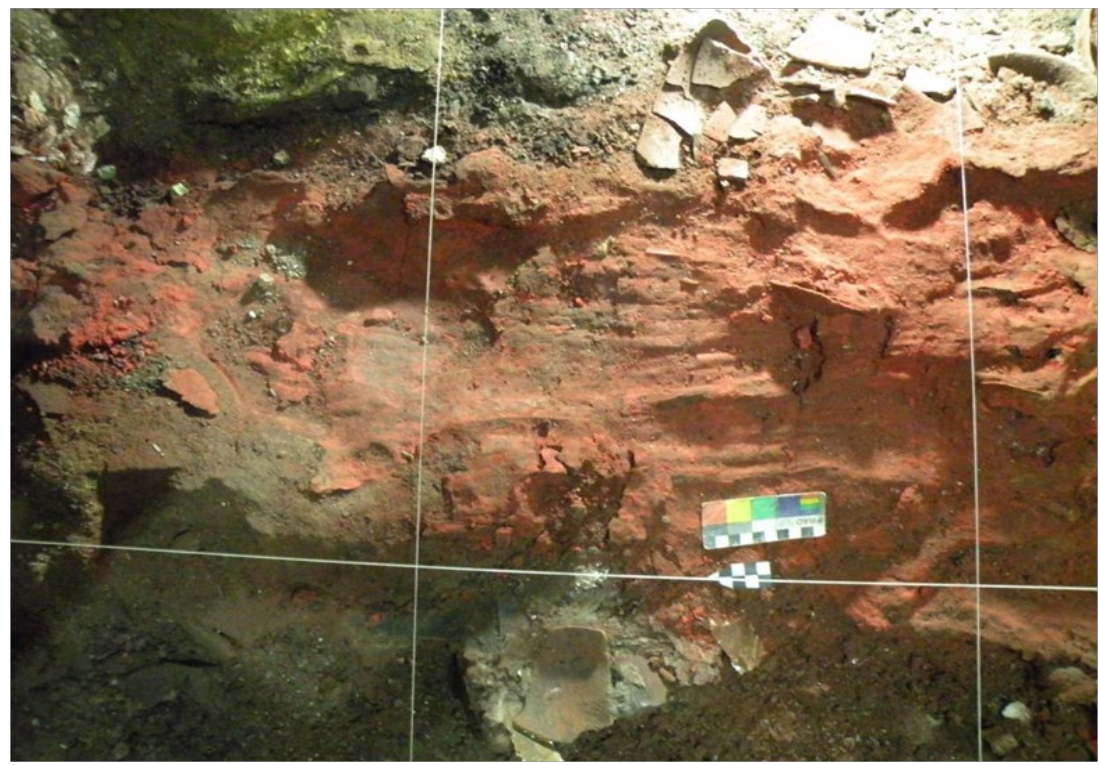

Figura 25. Pigmento rojo sobre el lecho de la tumba. (Foto: M.E. Garza)

El conjunto de las ofrendas, así como la ubicación de la tumba en el recinto mas privado y sagrado de la antigua ciudad de Copán, señalan que esta debe ser la tumba de uno de los primeros gobernantes de la misma. Estos objetos también nos indican sobre la firme afiliación de este reinado a la poderosa ciudad mexicana de Teotihuacán.

\section{CONCLUSIONES}

En conclusión podemos decir que para los Mayas tanto Oropéndola como Rosalila eran montañas sacrosantas en cuyos oscuros recintos, como cuevas sagradas, se realizaban ritos y ceremonias dedicados a venerar a los antepasados, y particularmente a los gobernantes enterrados en sus entrañas.

Oropéndola guarda muchas similitudes con Rosalila, particularmente en términos de sus características de arquitectura y construcción. Esto va de acuerdo con la proximidad espacial y temporal que nuestras excavaciones han determinado y que evidencian una continuidad tecnológica. En su arqueología, hemos podido determinar que aunque Oropéndola es un poco más tardía que Rosalila, ambas 
fueron construidos a mediados del VI Siglo después de Cristo en la cima de la acrópolis de aquel tiempo. Asimismo, las dos fueron enterradas y cubiertas por nuevas construcciones cerca de doscientos años más tarde, a mediados del VIII Siglo. El principal candidato para la construcción de los dos templos es el octavo gobernante, Wil Ohl K'inich, a la vez que el enterramiento debió ocurrir durante el reinado del decimotercer gobernante, Waxaklajún Ubah K'awil.

Los restos arqueológicos encontrados adentro de los dos templos tienen también sus similitudes, sin embargo había muchos más in situ adentro de Rosalila que en Oropéndola. De hecho este segundo edificio daba la impresión de haber sido limpiado antes de su enterramiento. Las ofrendas que vemos en común son de concha y jade, las cuales eran depositadas debajo de los pisos estucados en los ejes centrales de los edificios. De igual forma, ambos edificios tenían tableros de patollis grabados en los pisos de los cuartos del segundo nivel.

Donde vemos un cambio radical entre los edificios es en la manera de decorar sus fachadas de los mismos, pasando de grandes volúmenes en estuco modelado en Rosalila a mosaicos de toba recubiertas con delgadas capas de estuco en Oropéndola.

En términos de su iconografía, cada edificio tiene su propio programa. En el caso de Rosalila, el principal tema iconográfico representado en sus fachadas es el Dios del Sol, K'inich Ahau, quien es relacionado directamente con el fundador de la dinastía copaneca, K'inich Yax K'uk Mo'. En el caso de Oropéndola es el Dios Sol Nocturno representado en las figuras de los jaguares. Ambos edificios son marcados como montañas sagradas, witz, y tienen una multitud de otros elementos iconográficos de cosmología maya, muchos relacionados con la veneración de los antepasados y el poder de los reyes.

En términos de posicionamiento en la cima de la acrópolis antigua, Rosalila domina el oeste y por lo tanto se asocia con la puesta del sol y su paso al inframundo. Oropéndola se ubica al sur adonde se puede asociar directamente con el inframundo.

En todo caso, Oropéndola es ese gran laboratorio donde se dejan atrás los espléndidos tiempos del estuco modelado y se apuesta por un incipiente nuevo género de escultura basado en mosaicos de piedra, estilo que daría inicio a una gremio de escultores que llegaría a colocar a Copán entre las ciudades más sobresalientes del Mundo Maya. 


\section{BIBLIOGRAFÍA}

- Agurcia F, R., \& Pèrez, J. C. (2008). Oropéndola: Temple of the jaguar. III Congreso Internacional de Copán. Copán, Honduras.

- Agurcia F., R., \& Fash, W. L. (1991, September). Maya Artistry Unearthed. National Geographic Magazine, pp. 94-105.

- Agurcia Fasquelle, R. (1997). Le temple du roi Soleil et son evolution au coeur de l'acropole de Copán. Les Mayas au Pays de Copán, 336-355.

- Agurcia Fasquelle, R., Sheets, P., \& Taube, K. A. (2016). Protecting Sacred Space: Rosalila's eccentric cache at Copán and eccentrics among the Classic Maya. Monograph 2.

- Agurcia, R., Stone, D., \& Ramos, J. (1996). Tierra, tiestos, piedras, estratigrafía y escultura: Investigaciones en la Estructura 10L-16 de Copán. (W. Fash, Ed.) Visión del Pasado Maya, 185-201.

- Andrews, E. W., \& Fash, W. L. (2005). Copán: The Histoy of an Ancient Maya Kingdom. Santa Fe: School of American Research Press.

- Ballinger, D. A., \& Stomper, J. (n.d.). The Jaguars of Altar Q, Copán, Honduras: Faunal analysis, archaeology and ecology. Journal of Ethnobiology 20(2), 223236.

- Bell, E., Canuto, M., \& Sharer, R. (2004). Rosalila, Temple of the Sun-King. Early Classic Copán.

- Bell, E., Canuto, M., \& Sharer, R. (2004). Understanding Early Classic Copán. Philadelphia: University of Pennsylvania Museum.

- Calvin, I. (n.d.). Escritura Maya. Retrieved from http://www.famsi.org/spanish/ mayawriting/calvin/royal_dynasties_es_i.pdf

- Careta, N. (2001). Fauna Mexica: Naturaleza y simbolismo.The Netherlands: Research School CNWS, Leiden University.

- Chinchilla Mazariegos, O. (1997). Corpus de escultura estilo Cotzumalguapa. 
- Chinchilla Mazariegos, O. (1997). Corpus de escultura estilo Cotzumalguapa. Retrieved from FAMSI: http://www.famsi.org/reports/96008/index.html

- Cobos, R. (2005, Marzo-abril ). Jaguares y pumas de Tula y Chichón Itzá. Semejanzas y diferencias. Arqueología Mexicana, XII (72), 34-39.

- Conides, C. (2001). The Stuccoed and Painted Ceramics from Teotihuacán, Mexico: A Study in Authorship and Function of Works of Art from an Ancient Mesoamerican City. Ph.D Dissertation. Columbia University.

- Cortez, C. (1986). The Principal Bird Deity in Preclassic and Early Classic Maya Art. Unpublished Master of Arts Thesis, The University of Texas at Austin.

- De La Garza, M. (1995). Aves Sagradas de los Mayas. México: UNAM.

- El espacio mítico del rey maya en el periodo Clásico. (1995). TRACE , 28, 2952.

- Fash, B. W. (1992). Late Classic Architectural Sculpture Themes in Copán. Ancient Mesoamerica(3), 89-104.

- Fash, W. L., \& Agurcia Fasquelle, R. (1996). Visión del Pasado Maya. San Pedro Sula: Centro Editorial.

- Fash, W. S. (2001). Thames \& Hudson Ltd. London.

- Fields, V. (Ed.). (1985). The Sun Kings at Copán and Quiriguá. Fifth Palenque Round Table (pp. .29-38). San Francisco: Pre-Columbian Art Research Institute.

- Freidel, D., Schele, L., \& Parker, J. (1993). Maya Cosmos: Three Thousand Years on the Shaman's Path. New York: William Morrow and Company, Inc.

- Hellmuth, N. M. (1986). Monsters und Menschen ib der Maya-Kunst. Akademische Druck-u.Verlagsanstalt, Graz.

- Kidder, A. V., Jennings, J. D., \& Shook, E. M. (1946 ). Excavations at Kaminaljuyu, Guatemala , Publication 561. Washington D.C.: Carnegie Institution of Washington.

- Los templos enmascarados de Yucatán. (1999, Mayo-junio ). Arqueología Mexicana, VII (37), 54-59. 
- Martin, S., \& Grube, N. ( 2000). Chronicle of Maya Kings and Queens. London: Themes and Hudson.

- Miller, M. E. (1986). Copán, Honduras : Conference with a Perished City. (E. P. Benson, Ed.) 72-108.

- Miller, M. E., \& Taube, K. (1993). The Gods and Symbols of Ancient Mexico and the Maya. Londres: Thames and Hudson.

- P.Schmidt, Garza, M. I., \& Nalda, E. (1998). Copán: Art, Science and Dynasty. Maya, 336-355.

- Peabody Museum Press, Cambridge. (2011). The Copán Sculpture Museum: Ancient Maya artistry in stucco and stone.

- Pérez Calderón, J. C. (2002). El sistema constructivo de Oropéndola, una edificación del Período Clásico Tardío en la Acrópolis de Copán. Tesis de Grado. Guatemala: Escuela de Historia. Universidad de San Carlos de Guatemala.

- Pérez Calderón, J. C. (2004, Diciembre). Consideraciones sobre el sistema constructivo de Oropéndola, una edificación del Clásico Tardío en la Acrópolis de Copán. Utz ỉ, 3 ( 7), 1-13.

- Polgar Salcedo, M. (2005, Marzo-abril ). El jaguar prehispánico. Huellas de lo divino. Temática de una exposición. Arqueología Mexicana, XII (72), 66-69.

- Pragner, C., \& Wagner, E. (2008). Historical Implications of the Early Classic Hieroglyphic Text on the Step of Structure 10L-11-Sub-12 at Copán (CPN 3033). Manuscript.

- Quintal Suaste, B. (1999, Mayo-junio). Los mascarones de Acanceh. Arqueología Mexicana, VII (37), 14-17.

- Ramos, J. (2003). Investigaciones en el Templo16: Una reconstrucción en curso de la imaginería del Templo 16, Copán, Honduras. Retrieved from FAMSI: http://www.famsi.org/reports/02098es/index.html

- Saturno, William, Taube, K., \& Stuart, D. (2005). Los murales de San Bartolo, El Petén, Guatemala, parte 1: El mural del norte. Ancient America 7.

- Saunders, N. J. (2005, Marzo-abril ). El icono felino en México. Fauces, garras y uñas. Arqueología Mexicana, XII (72), 20-27. 
- Schele, L., \& Miller, M. (1986). The Blood of Kings: Dynasty and Ritual in Maya Art. Fort Worth: Kimbell Art Museum.

- Sharer, R., Traxler, L., Sedat, D., Bell, E., Canuto, M., \& Powell, C. (1999). Early Classic Architecture Beneath the Copán Acropolis: A Research Update. Ancient Mesoamerica, 10:3-23.

- Sugiyama, N., \& Fash, W. L. (n.d.). Una reinterpretación de los felinos de Copán: Reconstrucción de la colección "Sopa de jaguares" en el Altar Q. Yaxkin.

- Taube, K. (1993). Myths., Aztec and Maya.

- Taube, K. (2000). The Turquoise Hearth: Fire, Self-Sacrifice, and the Central Mexican Cult of War. In Mesoamerica's Classic Heritage: From Teotihuacan to the Aztec. (D. Carrasco, L. Jones, \& S. Sessions, Eds.) 269-340.

- Taube, K. (2004). Flower Mountain: Concepts of life, beauty, and paradise among the Classic Maya. RES (45), 69-98.

- Taube, k. (2004). Structure 10L-16 and Its Early Classic Antecedents: Fire and the Evocation and Resurrection of K'inich Yax K'uk' Mo'. (E. Bell, M. Canuto, \& R. Sharer, Eds.) Understanding Early Classic Copán, 265-295.

- Taube, K. (2016). El portador de la lluvia/The Bringer of Rain. Artes de México (121), 16-21, 67-69.

- Taube, K. A. (1992). The Major Gods of Ancient Yucatan.

- Taube, K. A. (2010). The Murals of San Bartolo, El Petén, Guatemala, Part 2: The West Wall. Ancient America (10).

- Urcid Serrano, J. (2005, Marzo-abril ). El simbolismo del jaguar en el suroeste de Mesoamérica. Arqueología Mexicana, XII(72), 40-46.

- Valdés, V. ( 2005, Marzo-abril). El jaguar entre los mayas. Entidad oscura y ambivalente. Arqueología Mexicana, XII (72), 47-51.

- Valverde Valdés, M. d. ( 2004). Balam El jaguar a través de los tiempos y los espacios del universo maya.

- Viel, R. (2006 ). The Ceramic Chronology of Copán: a plotted history and some revisionist reflections. (S. U. Lilley, Ed.) An Archaeological Life: Papers in Honour of Jay Hall, 203-212. 
- Viel, R., \& Cheek, C. D. (1983 ). Sepulturas. In Introducción a la Arqueología de Copán, Honduras. (C. Baudez, Ed.) I.

- Zralka, J. (2014). Pre-Columbian Maya Graffiti: Context, Dating and Function. 